UNIVERSIDADE DE SÃO PAULO

FACULDADE DE ODONTOLOGIA DE RIBEIRÃO PRETO

LEONARDO RAPHAEL ZUARDI

Concentrações salivares, sanguíneas e plasmáticas de Óxido Nítrico em pacientes com Doença Periodontal antes e depois do tratamento periodontal não cirúrgico

Ribeirão Preto - SP 


\section{Concentrações salivares, sanguíneas e plasmáticas de Óxido Nítrico em pacientes com Doença Periodontal antes e depois do tratamento periodontal não cirúrgico}

Dissertação apresentada à Faculdade de Odontologia de Ribeirão Preto da Universidade de São Paulo para obtenção do título de Mestre em Reabilitação Oral.

Área de concentração: Biologia Oral

Orientadora: Prof ${ }^{\mathrm{a}}$. Dr ${ }^{\mathrm{a}}$. Raquel Fernanda Gerlach

Versão Original

Ribeirão Preto 


\section{É AUTORIZADA A REPRODUÇÃO TOTAL OU PARCIAL DESTE CONTEÚDO, POR QUALQUER MEIO, SEJA ELE CONVENCIONAL OU ELETRÔNICO, PARA FINS DE ESTUDO E PESQUISA, DESDE QUE CITADA A FONTE.}

FICHA CATALOGRÁFICA

\section{Zuardi, Leonardo Raphael}

Concentrações salivares, sanguíneas e plasmáticas de Óxido Nítrico em pacientes com Doença Periodontal antes e depois do tratamento periodontal não cirúrgico. Ribeirão Preto, 2012.

82 p.: il. ; $30 \mathrm{~cm}$

Orientadora: Gerlach, Raquel Fernanda

Dissertação de Mestrado, apresentada à Faculdade de Odontologia de Ribeirão Preto/USP. Área de concentração: Biologia Oral.

1. Óxido Nítrico. 2. Plasma. 3. Saliva

4. Doença Periodontal. 
FOLHA DE APROVAÇÃO

LEONARDO RAPHAEL ZUARDI

Concentrações salivares, sanguíneas e plasmáticas de Óxido Nítrico em pacientes com Doença Periodontal antes e depois do tratamento não cirúrgico

Dissertação apresentada à Faculdade de Odontologia de Ribeirão Preto da Universidade de São Paulo para obtenção do título de Mestre em Reabilitação Oral.

Área de concentração: Biologia Oral

Aprovado em:

\section{Banca examinadora:}

Prof(a). Dr.(a): Raquel Fernanda Gerlach

Instituição: Faculdade de Odontologia de Ribeirão Preto- Universidade de São Paulo Assinatura:

Prof. Dr.:

Instituição: Assinatura:

Prof. Dr.:

Instituição: Assinatura: 
Dedico este compêndio aos meus familiares, em especial aos meus pais, que sempre me apoiaram nesta empreitada. Este é fruto do amor, educação e respeito às pessoas. 


\section{AGRADECIMENTOS}

Agradeço aos meus pais (Paulo Cesar Zuardi e Neri Alves dos Santos Zuardi), que me deram educação, amor e souberam me escutar nos momentos de alegria e principalmente nos momentos de tristeza e desespero ao longo desses anos. Essas folhas são poucas para agradecer tudo aquilo que se passa no meu coração.

Ao meu tio Prof. Dr. Antonio Waldo Zuardi, que acreditou em minha pessoa e proporcionou apoio em Ribeirão Preto desde 2004.

À Prof.(a) Dr.(a) Raquel Fernanda Gerlach que me aceitou em seu laboratório, desde 2005, me ensinou o que é ser professor e pesquisador, me escutou quando necessário e resolveu conjuntamente os problemas decorrentes. O meu muito obrigado pelo convívio, a solidariedade e a confiança.

Ao Prof. Dr. José Eduardo Tanus dos Santos pela ajuda neste trabalho.

A doutoranda Valéria Aguiar Gomes, pela enorme ajuda e compreensão, o meu muito obrigado de coração.

À colega C.D. Dr.(a) Andréa M. Marcaccini, por ter me proporcionado o gosto e interesse pela Periodontia. Assim como os professores da Periodontia FORP/USP.

Aos meus colegas de laboratório, que me aturaram e me ajudaram: Andréa Marcaccini, Élen Rizzi, Lívia Ferreri Hohne, Carolina Guerra, Isabel Porto Lelis, Glauce Almeida, Adriana Lima, Carla Speronni, Junia Ramos, Rafael, Bruna Cordeiro, Aline de Azevedo, Alisson Oliveira, Stêfany Cau, Anna Laura Jacob, Raquel Carros, Carlos Meloni, Gabriela Ferian Molina, Conrado Ingraci, Fellipe Figueredo. 
Aos meus amigos de disciplina e turma: Olívia Cherubin Alves, Cristiane Nogueira Bataglion, Gabriela Ferian Molina, Juliana Alves Peres, Glauce Clivelaro do Nascimento, Iliana Sabbatini, Yamba Pereira, Bruna Kotake, Maidy Ferreira, Marcelo Toniolo, Danilo Sorgini, Murilo, Rafael Cândido, Lourenzo Rego Roselino, Maria Paula Vecchia, Vanessa Fagundes, Karina Lencione, Nathalia Oliscoviscz, Anderson Paim, entre outros tantos.

Aos funcionários da Faculdade e do Departamento de Fisiologia Estomatologia e Morfologia: Dimitrius Pitol, Túlio Lopes, Clélia, Adalberto, Rosângela, Ana Paula Xavier, Fernanda de Freitas, Isabel Sola, Hermano Machado, Luiz Antonio Matarugo, Regiane Damasceno, Regiane Moi, Zilda Fernandes.

A Prof.(a) Fernanda de Carvalho Panzeri Pires-de-Souza, pelo incentivo e prontidão nas horas de dificuldade, o meu muito obrigado.

Aos todos os amigos da maravilhosa Faculdade de Odontologia de Ribeirão PretoUSP que mudaram o meu modo de ser e me transformaram em um ser humano pronto para enfrentar as dificuldades do mundo.

Ao apoio financeiro da Fapesp (Fundação de Amparo a Pesquisa do Estado de São Paulo) a este trabalho na forma de bolsa de Mestrado (Proc. 2009/13586-8) e Auxilio a Pesquisa (Proc. 2005/60527-6), apoio da CAPES (Coordenação de Aperfeiçoamento de Pessoal de Nível Superior).

A todos que contribuíram na minha formação, e me acolheram nestes 8 anos de Odontologia, o meu carinhoso muito obrigado. 
"A nossa maior glória não reside no fato de nunca cairmos, mas sim em levantarmo-nos sempre depois de cada queda" Confúcio. 


\section{RESUMO}

Zuardi, L. R. Concentrações salivares, sanguíneas e plasmáticas de Óxido Nítrico em pacientes com Doença Periodontal antes e depois do tratamento periodontal não cirúrgico. Ribeirão Preto, 2012. 82p. Dissertação (Mestrado em Reabilitação Oral) - Faculdade de Odontologia de Ribeirão Preto, Universidade de São Paulo, Ribeirão Preto, 2012.

O Óxido Nítrico (NO) faz parte de uma família de radicais livres que está envolvida em várias funções do organismo como controle cardiovascular, homeostase, formação óssea, neurotransmissão e funções imunológicas. Tem sido descrito que o NO atuaria na resposta de defesa do hospedeiro frente à infecção dos tecidos orais. Por outro lado, tem sido descrito também que quantidades excessivas de NO podem contribuir para a destruição tecidual na periodontite. Além destes aspectos muito importantes na boca, o NO é uma das moléculas de maior importância para a saúde humana, pois a sua liberação pelo endotélio dos vasos é um componente fundamental para o controle da pressão arterial. Já foi demonstrado que bactérias comensais da boca seriam responsáveis pela produção de nitritos que, no estômago, seriam convertidos a NO e este absorvido. Como as quantidades de nitrito na saliva são cerca de mil vezes maiores do que aquelas detectadas no sangue total, acredita-se que o nitrito da saliva possa ter repercussão no NO do sangue total e possivelmente possa também ter algum efeito na regulação de eventos sistêmicos, como a própria pressão arterial. O número de trabalhos sobre $\mathrm{NO}$ na saliva encontrados na literatura científica de língua inglesa não soma 2 dezenas, e pela importância do assunto, faz-se necessário conhecer em detalhes as concentrações de nitrito nos diferentes tipos de saliva, no sangue total, eritrócitos e plasma em pacientes com doença periodontal e controles, antes e depois do tratamento. As hipóteses deste estudo são: 1- Que as concentrações de nitrito sejam menores na saliva total de indivíduos com doença periodontal e que estas aumentem após o tratamento periodontal; 2- Que haveria o mesmo perfil de variação nas concentrações de nitrito no sangue total, eritróticos e plasma vista na saliva total. No presente estudo avaliaram-se as concentrações de NO na saliva total, saliva sumandibular/sublingual, parotídea, no sangue total, eritrócitos e plasma de pacientes controle e pacientes com doença periodontal crônica, com coletas antes e 3 meses após o tratamento periodontal não cirúrgico. A seguir testou-se se eram significativas as diferenças entre os valores obtidos antes e após o tratamento e foram comparados os perfis dos resultados de nitrito na saliva e sangue total. Foram realizadas as dosagens de NO pelo método de análise de quimiluminescência. Os resultados obtidos mostraram que em todos os parâmetros clínicos houve diferença estatisticamente significante antes e após o tratamento periodontal (DPA e DPD), nos grupos controle antes e depois do tratamento (CA e CD) e nos controles antes e doentes antes do tratamento (CA e DPA).Sangramento a sondagem: (DPA versus DPD) $p<0,0001$, (CA versus CD) $p=0,0005$, (CA versus DPA) $p<0,0001$. Nivel clinico de inserção: (DPA versus DPD) $p<0,0001$, (CA versus CD) $p=0,01$, (CA versus DPA) $p<0,0002$. Profundidade de sondagem: (DPA versus DPD) $p<0,0001, \quad$ (CA versus DPA) $p<0,0001$. Sítios maiores que $4 \mathrm{~mm}$ : (DPA versus DPD) $p<0,0001$, (CA versus DPA) $p<0,0001$. Tal fato confirma um tratamento periodontal realizado com sucesso. Na saliva total, houve significante diminuição das concentrações de NO 
entre os controles antes e os doentes antes do tratamento (CA versus PDA), com $p=$ 0,04 . No sangue total houve diminuição das concentrações de $\mathrm{NO}$ antes e após o tratamento periodontal (DPA versus DPD), $p=0,026$. Já nos eritrócitos antes e após o tratamento (DPA versus DPD) houve significante diminuição, $p=0,02$. As concentrações de nitrito na saliva total tiveram medianas igual a 0,69 (Q1: 0,46/ Q3: 1,44) no grupo $C A$, mediana de $0,55(Q 1: 0,39 / Q 3: 1,55)$ no grupo $C D$, mediana de 0,44 (Q1: 0,26/ Q3: 0,81) no grupo DPA e mediana de 0,38 (Q1: 0,22/ Q3: 0,69) no grupo DPD. As concentrações de nitrito na saliva submandibular/sublingual tiveram medianas igual a 1,86 (Q1: 0,61/ Q3: 4,59) no grupo CA, mediana de 0,64 (Q1: 1,82/ Q3: 4,37) no grupo CD, mediana de 2,37 (Q1: 0,47/ Q3: 4,79) no grupo DPA e mediana de 2,69 (Q1: 1,69/ Q3: 3,43) no grupo DPD. As concentrações de nitrito na saliva parotídea apresentaram médias de 0,58 , e desvio padrão de 0,32 no grupo CA, média de 0,69 e desvio padrão de 0,33 no grupo $C D$, média de 0,69 e desvio padrão de 0,36 no grupo DPA e média de 0,85 e desvio padrão de 0,58 no grupo DPD. As concentrações de nitrito no sangue total tiveram medianas igual a 1,41 (Q1: 1,1/ Q3: 2,21) no grupo CA, mediana de 0,99 (Q1: 0,58/ Q3: 2,11) no grupo CD, mediana de 1,61 (Q1: 1,12/ Q3: 2,3) no grupo DPA e mediana de 1,45 (Q1: 0,61/ Q3: 0,87$)$ no grupo DPD. As concentrações de nitrito nos plasma tiveram medianas igual a 0,51 (Q1: 0,36/ Q3: 1,09) no grupo CA, mediana de 0,63 (Q1: 0,56/ Q3: 1,82) no grupo CD, mediana de 0,60 (Q1: 0,37/ Q3: 0,97) no grupo DPA e mediana de 0,5 (Q1: 0,39/ Q3: 0,83) no grupo DPD. As concentrações de nitrito no eritrócitos apresentaram médias de 0,45 e desvio padrão de 0,41 no grupo CA, média de 0,46 e desvio padrão de 0,47 no grupo $C D$, média de 0,57 e desvio padrão de 0,44 no grupo DPA e média de 0,29 e desvio padrão de 0,22 no grupo DPD. As concentrações de nitrito foram da ordem de micromolar na saliva e de nanomolar no sangue total, guardando uma relação de cerca de 1000 vezes entre estes 2 fluidos. As concentrações de nitrito obtidas foram decrescentes na seguinte ordem: saliva total, saliva sumandibular/sublingual, saliva parotídea, eritrócitos sangue total e plasma. Na saliva, os pacientes do grupo DPA e DPD apresentaram concentrações menores de nitrito em relação ao CA e CD ( $p<0.05)$, e o tratamento periodontal não teve efeito sobre as concentrações de nitrito. Também houve diminuição estatisticamente significante nas concentrações de nitrito no sangue total e eritrócitos após o tratamento periodontal (DPA versus DPD). Os resultados sugerem que não há relação entre as concentrações salivares e sanguíneas de nitrito. As concentrações salivares diminuídos depois do tratamento em pacientes com doença periodontal podem talvez estar associados com aumento dos níveis de arginase. Além disso, aumento nas concentrações sanguíneas de nitrito parecem estar associados aos aumentos de mediadores inflamatórios como IL-6, proteina C reativa, entre outros. As concentrações de nitrito no sangue total sugerem que a diminuição após o tratamento possa ser resultado da diminuição na atividade inflamatória nos pacientes com doença periodontal, já caracterizada anteriormente neste grupo de pacientes.

Palavras- Chave: Óxido nítrico, doença periodontal, saliva, sangue, plasma 


\section{ABSTRACT}

Zuardi, L.R. Salivary, blood and plasma concentrations of nitric oxide in patients with periodontal disease before and after non-surgical periodontal treatment. Ribeirão Preto, 2012. 82p. Dissertação (Mestrado em Reabilitação Oral) Faculdade de Odontologia de Ribeirão Preto, Universidade de São Paulo, Ribeirão Preto, 2012.

The Nitric Oxide (NO) is part of a family of free radicals that are involved in various bodily functions such as cardiovascular control, homeostasis, bone formation, neurotransmission and immune functions. It has been reported that $\mathrm{NO}$ act in response to host defense against infection of the oral tissues. Moreover, it has also been described that excessive amounts of NO can contribute to the periodontal tissue destruction. In addition to these very important aspects in the mouth, NO is a molecule of major importance to human health, since its release by the endothelium of blood vessels is a critical component to blood pressure control. It has been demonstrated that commensal bacteria of the mouth would be responsible for production of nitrites, in the stomach, be converted to $\mathrm{NO}$ and this be absorbed. The amount of nitrite in the saliva is about one thousand times greater than those detected in whole blood, it is believed that the nitrite saliva may have the effect of whole blood and NO can also possibly have an effect on regulation of systemic events as the proper blood pressure. The number of papers on NO in the saliva found in the literature of the English language does not add 2 tens, and the importance of the subject, it is necessary to know in detail the concentrations of nitrite in different types of saliva, whole blood, erythrocytes and plasma in patients with periodontal disease and controls before and after treatment. The hypotheses of this study are: 1 - That the nitrite concentrations are lower in whole saliva of individuals with periodontal disease and that they increase after periodontal treatment, 2 - What there would be the same profile of variation in the concentrations of nitrite in blood, erythrocytes and plasma seen in the whole saliva. In the present study were evaluated the concentrations of $\mathrm{NO}$ in whole saliva, salivasumandibular / sublingual, parotid, whole blood, erythrocytes and plasma of control patients and patients with chronic periodontits, with collections before and three months after non-surgical periodontal treatment. The following were tested if significant differences between the values obtained before and after treatment were compared and the profiles of the the results of nitrite in the saliva and blood. Were performed measurements of $\mathrm{NO}$ by Chemiluminescence analysis method. The results showed that in all clinical parameters were statistically significant differences before and after periodontal treatment (DPA and DPD) in the control groups before and after treatment (CA and CD) and controls before and patients before treatment (CA and DPA). Bleeding on Probe (DPA versus DPD) $p<0,0001$, (CA versus CD) $p=0,0005$, (CA versus DPA) $p<0,0001$. Clinical attachment level: (DPA versus DPD) $p<0,0001$, (CA versus $C D) p=0,01$, (CA versus DPA) $p<0,0002$. Probing depth: (DPA versus DPD) $p<0,0001$, (CA versus DPA) $p<0,0001$. Sites larger than $4 \mathrm{~mm}$ : (DPA versus DPD) $p<0,0001$, (CA versus DPA) $p<0,0001$. This fact confirms a periodontal treatment performed successfully. In whole saliva, a significant decrease in NO concentration between controls and patients before treatment (CA versus PDA), with $p=0.04$. Whole blood decreased 
NO concentration before and after periodontal treatment (DPA versus DPD), $p=$ 0.026 . Already in erythrocytes before and after treatment (DPA versus DPD) there was a significant decrease, $p=0.02$. The concentrations of nitrite in whole saliva had median equal to 0.69 (Q1: 0.46 / Q3:1.44) in group CA, a median of 0.55 (Q1: 0.39 / Q3: 1.55) in CD group, median 0.44 (Q1: 0.26 / Q3: 0.81) in the DPA and a median of 0.38 (Q1: 0.22 / Q3: 0.69) in the DPD. The concentrations of nitrite in saliva submandibular / sublingual medians were equal to 1.86 (Q1: 0.61 / Q3: 4.59) in group CA, a median of 0.64 (Q1: 1.82 / Q3: 4.37 ) in the CD and a median of 2.37 (Q1: 0.47 / Q3: 4.79) in the DPA and a median of 2.69 (Q1: 1.69 / Q3: 3.43) in the DPD. The nitrite concentrations in parotid saliva showed mean of 0.58 and standard desviation of 0.32 in the CA group, mean 0.69 and standard deviation of 0.33 in CD group, mean 0.69 and standard deviation of DPA and 0.36 in the group average of 0.85 and standard deviation of 0.58 in the DPD group. The concentrations of nitrite in whole blood were median equal to 1.41 (Q1: 1.1 / Q3: 2.21) in group CA, a median of 0.99 (Q1: 0.58 / Q3: 2.11) in CD group, median 1.61 (Q1: 1.12 / Q3: 2.3) in the DPA and a median of 1.45 (Q1: 0.61 / Q3: 0.87) in the DPD. The plasma concentrations of nitrite in the medians were equal to 0.51 (Q1: 0.36 / Q3: 1.09) in group CA, a median of 0.63 (Q1: 0.56 / Q3: 1.82) in group CD and a median of 0.60 (Q1: 0.37 / Q3: 0.97) in the DPA and a median of 0.5 (Q1: 0.39 / Q3: 0.83) in the DPD. The concentrations of nitrite in erythrocytes showed averages of 0.45 and standard deviation of 0.41 in the CA group, mean 0.46 and standard deviation of 0.47 in the CD group, mean 0.57 and standard deviation of 0,44 DPA and the group average of 0.29 and standard deviation of 0.22 in DPD group. The nitrite concentrations were in the order of micromolar and nanomolar saliva in whole blood, keeping a ratio of about 1000-fold between the two fluids. The concentrations of nitrite were obtained in the following descending order: whole saliva, saliva submandibular / sublingual, parotid saliva, whole blood, erythrocytes and plasma. In saliva, the patients in the PDA and DPD showed lower concentrations of nitrite in relation to CA and CD $(p<0.05)$, and periodontal treatment had no effect on concentrations of nitrite. There was also a statistically significant decrease in nitrite concentrations in whole blood and erythrocytes after periodontal treatment (DPA versus DPD). The results suggest that there is no relationship between the salivary and blood concentrations of nitrite. Salivary levels decreased after treatment in patients with periodontal disease may perhaps be associated with increased levels of arginase. Furthermore, increased blood concentration of nitrite may be associated with increases in inflammatory mediators such as IL-6, C-reactive protein, among others. The nitrite concentrations in whole blood suggest that reduced after treatment may be a consequence of diminished inflammatory activity in patients with periodontal disease, characterized already earlier in this group of patients.

Keywords: Nitric oxide, saliva, blood, plasma 


\section{LISTA DE ILUSTRAÇÕES}

Figura 1 - Esquema demonstrativo da cascata reacional de óxido nítrico 30

Figura 2- Gráfico do sangramento a sondagem 50

Figura 3- Gráfico do nível Clínico de inserção. 51

Figura 4- Gráfico da profundidade de sondagem 52

Figura 5-Gráfico dos sítios com profundidade de sondagem $>4 \mathrm{~mm}$ 53

Figura 6-Gráfico das concentrações de nitrito na saliva total 54

Figura 7- Gráfico das concentrações de nitrito na saliva parotídea. 55

Figura 8- Gráfico das concentrações de nitrito na saliva submandibular/ sublingual 56

Figura 9- Gráfico das concentrações de nitrito no sangue total. 57

Figura 10- Gráfico das concentrações de nitrito no plasma 58

Figura 11- Gráfico das concentrações de nitrito em eritrócitos 59

Reação 1- Reação entre o óxido nítrico e o ozônio 46 


\section{LISTA DE ABREVIATURAS, SIGLAS E SÍMBOLOS}

$\%=$ percentual

${ }^{\circ} \mathrm{C}=$ graus Celsius

$\mu \mathrm{M}=$ micromolar

$\mathrm{AVC}=$ acidente vascular cerebral

$\mathrm{BOP}=$ Sangramento a Sondagem

$\mathrm{CA}=$ Controle antes do tratamento

$\mathrm{CAL}=$ Nível Clínico de Inserção

$\mathrm{CD}=$ Controle depois do tratamento, 3 meses

$\mathrm{DP}=$ Doença Periodontal

eNOS= Óxido Nítrico Sintetase endotelial

$\mathrm{ER}=$ Eritrócitos

FORP/USP = Faculdade de Odontologia de Ribeirão Preto Universidade de São Paulo

g= gravidade

GFAP= proteína glial fibrilar ácida

$\mathrm{h}=$ hora

$\lg A=$ Imunoglobulina $A$

$\lg E=$ Imunoglobulina $E$

$\mathrm{IL}-10=$ Interleucina 10

IL-13= Interleucina 13

$\mathrm{IL}-1 \alpha=$ Interleucina 1 alfa 
IL-6= Interleucina 6

IL-8 = Interleucina 8

iNOS= Óxido Nítrico Sintetase induzível

$\mathrm{mg} / \mathrm{g}=$ miligrama por grama

MilliQ= água pura

$\mathrm{ml}=$ mililitro

$\mathrm{mm}=$ milímetros

MMP= Metaloproteina da matriz

$\mathrm{mV}=$ milivolt

$\mathrm{nM}=$ nano molar

nNOS= Óxido Nítrico Sintetase neuronal

$\mathrm{NO}=$ Óxido Nítrico

NOS= Óxido Nítrico Sintetase

$\mathrm{PCR}=$ Proteina $\mathrm{C}$ reativa

PD $=$ Profundidade de Sondagem

$\mathrm{PDA}=$ Doentes periodontais antes do tratamento

$\mathrm{PDP}=$ Doentes periodontais depois do tratamento, 3 meses

PGE= prostraglandila

$\mathrm{PL}=$ Plasma

rpm= rotações por minuto

SAT $=$ Saliva Total

SNT= Sangue Total 
SOD= Superóxido dismutase

SP= Saliva Parotídea

SSUB $=$ Saliva submandibular e sublingual

STE $=$ Saliva Total Expectorada

TCLE= Termo de Consentimento Livre e Esclarecido

TIMP= Inibidor tecidual de metaloproteina

TIMP-4= Inibidor tecidual de metaloproteina 4

TNF- $\alpha=$ Fator de Necrose Tumoral alfa

$\alpha$ amilase $=$ alfa amilase 


\section{SUMÁRIO}

1 INTRODUÇÃO

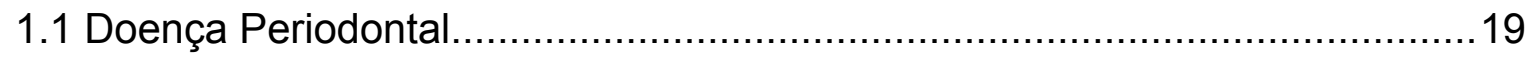

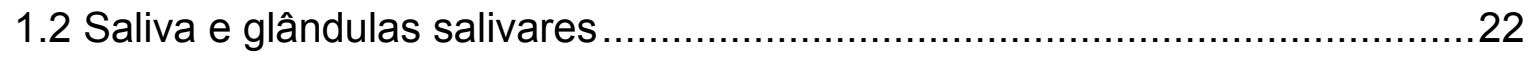

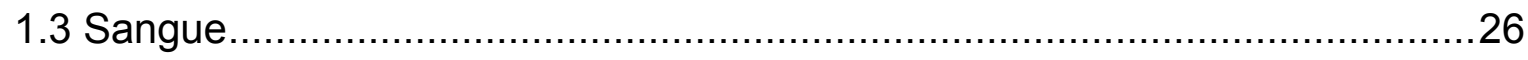

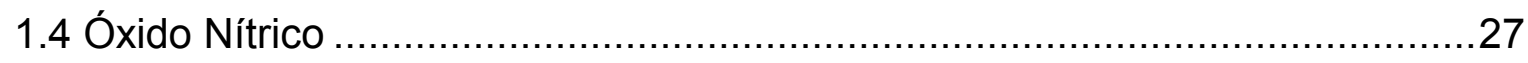

4. MATERIAL E MÉTODO

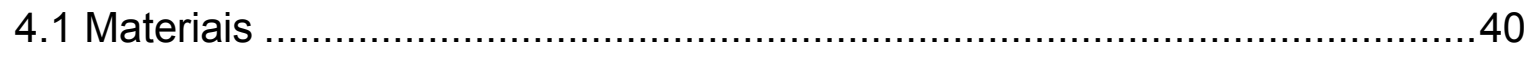

4.1.1 Materiais utilizados na etapa clínica ..................................................40

4.1.2 Soluções utilizadas na etapa laboratorial............................................. 41

4.1.3 Equipamentos utilizados na etapa laboratorial ...................................41

4.1.4 Programas de aquisição de dados...............................................42

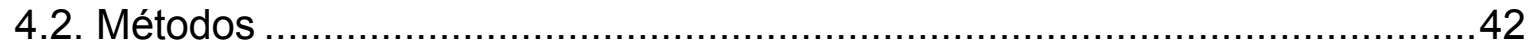

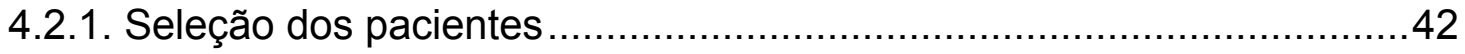

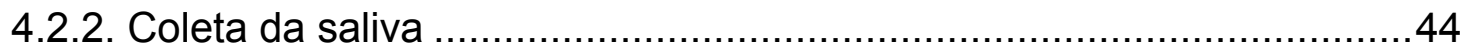

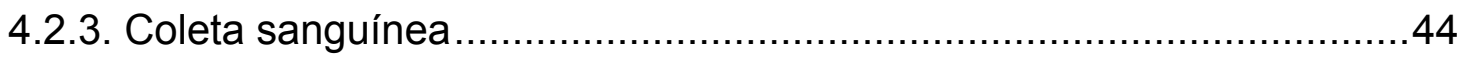

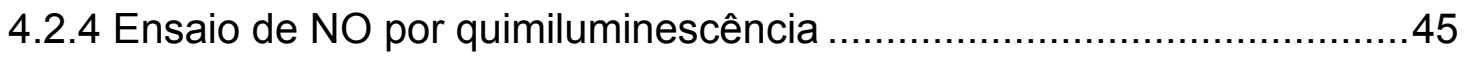

4.2.5. Análise Estatística........................................................................

5. RESULTADOS

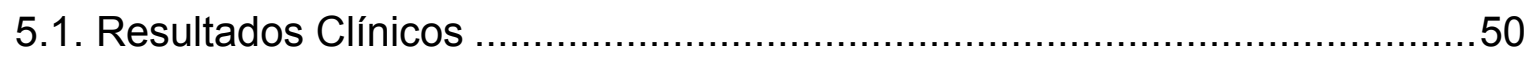

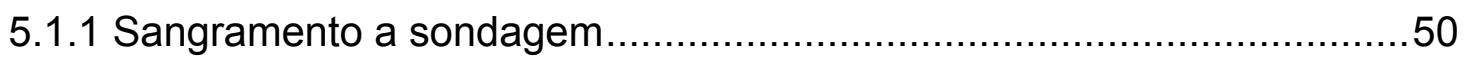

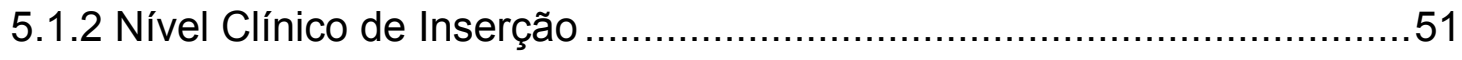

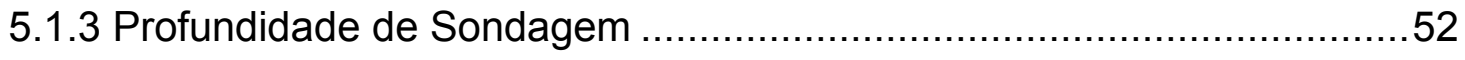

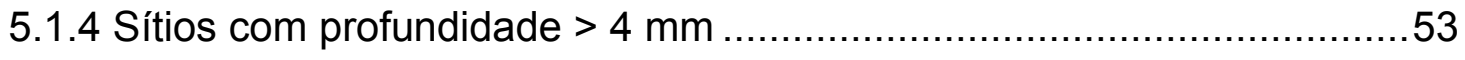

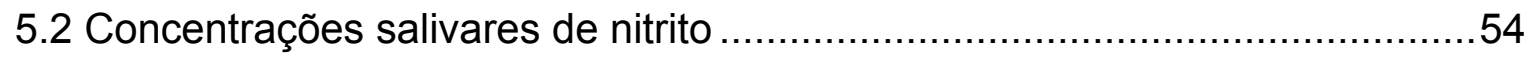

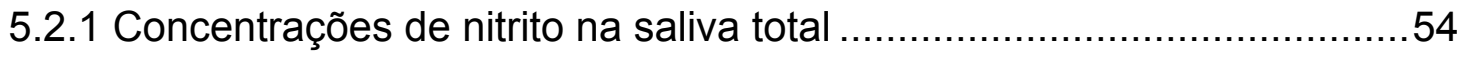

5.2.2 Concentrações de nitrito na saliva parotídea.......................................55 
5.2.3 Concentrações de nitrito na saliva submandibular e sublingual .56

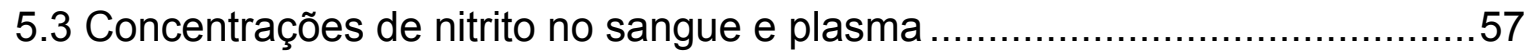

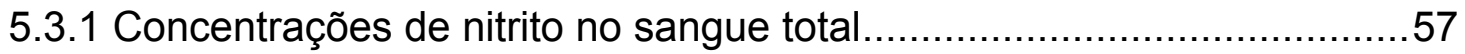

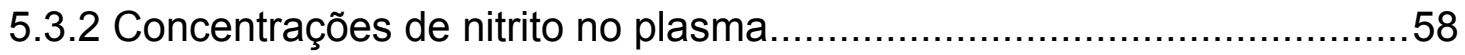

5.3.3 Concentrações de nitrito em eritrócitos.............................................59

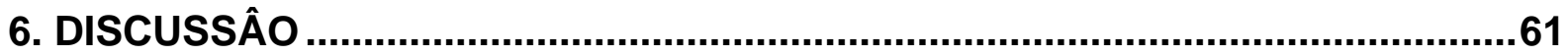

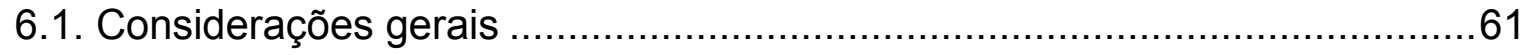

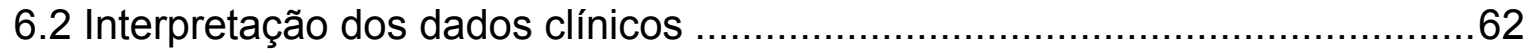

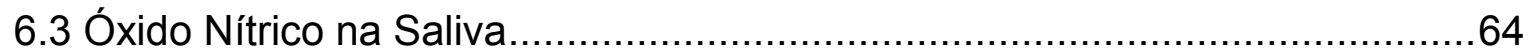

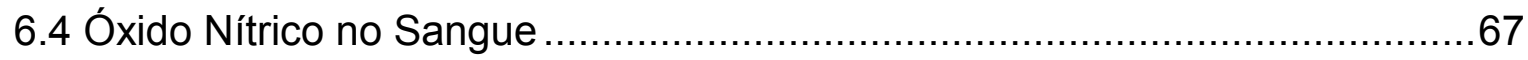

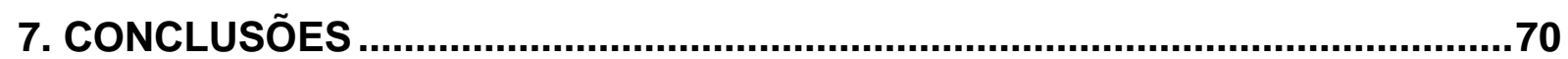

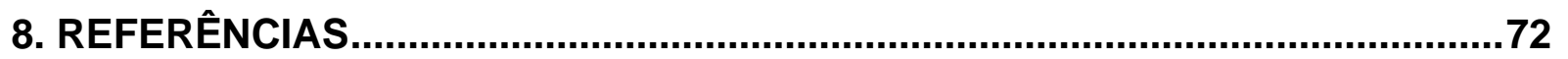




\section{INTRODUÇÃO}

\subsection{Doença Periodontal}

$\mathrm{Na}$ cavidade oral encontramos, dentre tantos tecidos, o periodontal, o qual compreende o periodonto de sustentação (osso alveolar, ligamento periodontal e cemento) e periodonto de proteção (gengiva) (TEN CATE, 2001a).

As funções atribuídas ao periodonto de sustentação são: a união dos elementos ósseos ao dente e a amenização de forças oclusais tanto maxilares quanto mandibulares, ambas através de fibras do ligamento periodontal. Esse controle é exercido via mecanoreceptores presentes nesta região (TRULSSON, 2006).

O periodonto pode ser acometido por uma doença denominada Doença Periodontal (DP).

Epidemiologicamente, a DP é principal causa de perda dos dentes em pacientes com mais de 35 anos de idade (NEVILLE et al., 2004). No Brasil é calculado que $85 \%$ da população adulta, com idade entre 35 a 40 anos, apresentem algum tipo de Doença Periodontal (PINTO, 1999; BRASIL, 2004).

Acima de tudo, a doença acomete o periodonto e pode restringir-se aos tecidos de proteção do dente, denominada gengivite, ou ainda, podem estender-se aos tecidos de suporte do dente, resultando na periodontite (PAGE, 1991; D'AIUTO et al., 2004). Muito embora não apresente fases agudas e crônicas bem definidas são descritas como lesões crônicas devido ao tempo que demoram para destruírem os tecidos adjacentes aos dentes (PAGE \& SCHOREDER, 1976). 
A DP é uma resposta imunológica do hospedeiro frente a um grupo de microorganismos específicos. O diagnóstico e classificação desta são baseados em parâmetros clínicos. Entretanto, avanços na biologia molecular e genética estão proporcionando um melhor entendimento dos mecanismos imunoinflamatórios de resposta frente a essa doença (SOCRANSKY \& HAFFAJEE, 2002).

Um dos fatores etiológicos principais da DP é o biofilme dental, o qual é acumulado a partir de uma fina película que se deposita ao longo da cavidade bucal, formada de restos de alimentos e células epiteliais descamadas (De LORENZO, 2004).

O cálculo dental é resultado da mineralização desse biofilme, pela absorção de íons cálcio e fosfato presentes na saliva e no fluido crevicular gengival (JIN \& YIP, 2002). Além da cavidade oral, as bactérias e seus subprodutos podem ser patogênicos a outros órgãos e sistemas (BECK et al., 1996; BECK et al., 2000, D'AIUTO et al., 2004).

Em conseqüência a processos físicos simples, tais como higiene dental e alimentação e procedimentos clínicos como raspagem, que lesam a mucosa e o tecido gengival, microrganismos presentes no biofiolme periodontal podem entrar na circulação sanguínea, causando assim, uma bacteremia transitória. $\mathrm{Na}$ doença periodontal, estes eventos de bacteremia são muito mais freqüentes em comparação com indivíduos saudáveis (FORNER et al., 2006).

Além disso, está documentado que a produção local (tecidos periodontais) das citocinas pró-inflamatórias tais como IL-6, TNF- $\alpha$, IL-1 e PGE 2 também podem migrar para a circulação e exercer efeitos sistêmicos ou a distância (GEMMEL et al., 1997; LOOS et al., 2000). 
Níveis circulantes aumentados de diversos marcadores inflamatórios em pacientes com DP e a diminuição desses níveis após o tratamento periodontal básico, foi relatado na literatura (MARCACCINI et al., 2009a).

Uma gama de mediadores inflamatórios, como citocinas e mediadores endógenos estão presentes no tecido periodontal, da mesma forma que são encontrados sistemicamente. Estes são gerados por células como leucócitos polimorfonucleares, fibroblastos, e participam tanto do processo patológico quanto na saúde periodontal (DIXON et al., 2004; LIU et al., 2010).

Em resumo, o processo de produção de mediadores inflamatórios se dá dessa forma: Citocinas pró-inflamatorias são produzidas pelas células do periodonto e do infiltrado inflamatório ${ }_{2}$ as quais são estimuladas pela presença de biofilme dental e seus metabólitos. Frente ao estimulo bacteriano, o epitélio do sulco gengival secreta citocinas, quimiocinas, tais como (IL-1 $\alpha, \mathrm{IL}-8, \mathrm{TNF}-\alpha)$ e há também liberação de neuropeptideos e histamina ocorrendo nesta primeira etapa. Começa então a liberação de proteínas séricas (sistema complemento), iniciando assim a resposta inflamatória. Em uma fase posterior ocorrem à infiltração de células mononucleares, plasmócitos e linfócitos, forma-se então o exsudato inflamatório. Por final, as células T são ativadas, conseqüentemente irão liberar várias citocinas e quimiocinas ( IL-10, IL-13, TNF- $\alpha$, entre outras).

Dessa forma, estabelece-se o processo inflamatório e microbiológico, o qual tem como resultado a DP.

Particularmente, certos indivíduos apresentam uma resposta imunológica exacerbada frente às bactérias periodontopatogênicas, o que pode levar a maiores níveis de destruição tecidual (SOCRANSKY \& HAFFAJEE , 1994; KORNMAN et. al.,1997; CARRANZA \& NEWMAN, 2002). Tal fato se deve a predisposição genética, 
a fatores adquiridos e ambientais, tais como cigarro e estresse. (LINDEN et al., 1996; PAGE, 1999; JOHNSON, 2001; HEITZ-MAYFIELD, 2005; HEASMAN et al., 2006; TIMMERMAN \& van der WEIJDEN, 2006).

Assim sendo, uma conjuntura de fatores como: biofilme, estresse, cigarro, predisposição genética, deficiência alimentar, entre outros, leva a instalação da doença. Portanto, a progressão da DP é dependente de uma interação complexa entre a virulência do biofilme e a imunidade do hospedeiro (TABA et al., 2005).

Desta feita, os tecidos afetados pela doença estabelecida têm como única alternativa, até o momento, o controle da doença como recurso paliativo na tentativa de conter a progressão e manter o elemento dental na cavidade oral. (KINANE et al., 2008).

\subsection{Saliva e glândulas salivares}

A saliva é um importante fator que proporciona um meio ambiente saudável na cavidade oral e é indispensável às reações de defesa desse meio (SATO et al., 2008).

A saliva é produzida por glândulas salivares maiores e menores, estas últimas microscópicas. Já as glândulas salivares maiores estão arranjadas em pares, e são: as glândulas parótidas, submandibulares e sublingual. (TEN CATE, 2001b).

As glândulas salivares parótidas se localizam bilateralmente na região inervada pelo nervo facial (VII), anteriormente a orelha e atrás do ramo da mandíbula. Enquanto que as glândulas salivares submandibulares e sublinguais, que são também bilaterais, recebem o nome da região que ocupam, respectivamente a porção posterior do assoalho da boca e entre a porção lateral da língua e os dentes. 
As glândulas salivares menores estão localizadas nas regiões labial, lingual, palatina, bucal, glossopalatina e retromolar.

Todas em conjunto são responsáveis pela produção de saliva total na cavidade oral.

As parótidas têm a capacidade de produzir um conteúdo seroso, rico em aamilase (enzima responsável pela degradação do amido proveniente da alimentação), água e proteínas albuminóides. Quando estimuladas contribui com mais da metade do volume salivar. Entretanto, quando não estimuladas, sua contribuição se reduz, e a saliva de origem submandibular sobrepuja em quantidade o conteúdo parotídeo. Em comparação com a secreção parotídea, a secreção submandibular ou sublingual é mais viscosa e rica em glicoproteinas como a mucina, responsável pela lubrificação e proteção da cavidade oral (ALMSTAHL \& GROENINK, 2001; GUYTON \& HALL, 2006; PEDERSEN et al., 2002).

Um indivíduo saudável tem a taxa de salivação total varia entre 500 a 1.000 $\mathrm{ml} /$ dia. A saliva total é uma mistura de componentes produzidos e secretados pelas glândulas salivares parótideas, sublinguais e submandibulares, o que corresponde a $90 \%$ de seu volume. Encontramos na saliva total componentes não pertencentes às glândulas salivares como: secreções brônquio-nasais, fluido crevicular gengival, microorganismos, resíduos da alimentação, soro, sangue derivados de ferimentos e células epiteliais esfolheadas. (GREABU et al., 2009)

No entanto, os efeitos da diminuição da secreção salivar total estão associados aos problemas de dificuldades na fala, deglutição, presença de úlceras aftosas, presença de cáries rampantes e, principalmente, a maior prevalência de doença periodontal em indivíduos com xerostomia (SHIBOSKI et al., 2007). 
A secreção da saliva é uma operação em dois estágios: o primeiro envolve os ácinos e o segundo envolve os ductos salivares. Os ácinos produzem uma secreção primária que contêm ptialina e/ou mucina em uma concentração não muito diferentes daquelas típicas dos líquidos extracelulares. À medida que a secreção primária flui através dos ductos, ocorrem dois importantes processos de transporte ativo que modificam bastante a composição iônica da saliva.

Primeiro, os íons sódio são ativamente absorvidos, enquanto que os íons potássio são secretados, criando assim, uma baixa concentração de íons sódio na saliva e alta concentração de potássio. Forma-se uma negatividade elétrica nos ductos, fato que ocasiona uma reabsorção de cloreto. Portanto, a concentração de íons cloreto no liquido salivar cai a um nível muito baixo.

Em segundo lugar, os íons bicarbonato são secretados pelo epitélio ductal para o lúmen do ducto. Isto é, em parte, causado pela troca de bicarbonato por íons cloreto, e resulta de um processo secretório ativo.

No que tange a regulação nervosa, é principalmente via sinais nervosos parassimpáticos que se originam do núcleo salivatório superior e inferior no tronco cerebral. Estes núcleos são ativados mediante a estímulos como gustativos e táteis da língua, de outras áreas da boca e faringe. A estimulação simpática também pode aumentar um pouco a salivação, porém bem menos que a estimulação parassimpática. Um fator secundário que afeta a salivação é o suprimento de sangue para as glândulas, porque a secreção sempre requer os nutrientes adequados de sangue. Os sinais parassimpáticos que induzem a salivação também dilatam moderadamente os vasos, além disso, a própria salivação dilata diretamente os vasos sanguíneos, proporcionando a nutrição necessária, às células secretoras (GUYTON \& HALL, 2006). 
A saliva produzida por esse mecanismo, constitui-se de fluido hipotônico que umedece a cavidade oral e auxilia na sua homeostase. É composta principalmente por água, eletrólitos e moléculas orgânicas (MILLER et al., 2010).

No que tange o conteúdo liquido da saliva a parte aquosa tem origem dos capilares locais. A água entra nas glândulas salivares pelos canais de aquaporina (proteínas integrais de membrana), difusão intracelular entre outras vias extracelulares (HAECKEL \& HANECKE, 1996; VERKMAN et al., 2000).

Os componentes inorgânicos são: bicarbonato, sódio, potássio, fosfato, fluoreto, amônia e dióxido de carbono, entre outros. Os componentes orgânicos salivares são em partes sintetizados, armazenados e secretados pelas células acinares. Dentre os orgânicos podemos citar a lisozima, lactoperoxidase, mieloperoxidase e aglutinias, como glicoproteinas, mucinas, fibronectinas, macroglobulinas, anticorpos antibacterianos, antifúngicos, hemostáticos, fatores de crescimento, como o fator de crescimento epidermal e importantes imunoglobulinas como Imunoglobulina A ( $\lg A$ ) e Imunoglobulina $E$ (Ig E) (AMERONGEN \& VEERMAN, 2002).

Nagler et al. (2002) identificou na saliva concentrações de enzima e neuropeptídeos os quais atuam na manutenção da homeostase oral, assim como antioxidantes: o superóxido dismutase (SOD), a peroxidase e o ácido úrico, que combatem os radicais livres. Também podemos encontrar na saliva o óxido nítrico, como veremos adiante.

Dessa forma, comprovamos que os componentes salivares são em sua grande parte reflexo da vascularização local, conseqüentemente de muitas moléculas presentes no plasma, tornando-se uma fonte importante de diagnostico (FARNAUD et al., 2010). 


\subsection{Sangue}

Segundo Junqueira \& Carneiro (2004) o sangue é o liquido contido num compartimento fechado, o aparelho circulatório, que mantém em movimento regular e unidirecional, devido essencialmente às contrações rítmicas do coração. O volume total de sangue em uma pessoa normal é de aproximadamente $7 \%$ do seu peso corporal.

É composto principalmente por glóbulos sanguíneos e pelo plasma, parte liquida, na qual os primeiros estão suspensos. Os glóbulos sanguíneos são os eritrócitos ou hemácias, as plaquetas (fragmentos do citoplasma dos megacariócitos da medula óssea) e diversos tipos de leucócitos ou glóbulos brancos.

Estudos de coorte demonstraram que podem ser freqüentes na população patologias como anemia (VICENT et al., 2002; CORWIN et al., 2004). É definida como a falta de hemoglobina (molécula presente nos eritrócitos), com taxas menores que $12 \mathrm{~g} / \mathrm{dL}$ de sangue (KRAMER et al., 2009)

De acordo com Lorenzi (2006), a origem das células do sangue são as células pluripotentes, denominadas células tronco. Estas são divididas, embora teoricamente, em células embrionárias e células de tecido adulto. As primeiras são capazes de originar elementos de outros tecidos, já as do tecido adulto precursores hematopoéticos.

Em uma revisão de literatura, Krawiec \& Vorp (2012), estudando células do sangue, denominadas células tronco, concluiu que ao longo dos últimos anos, as células tronco adultas têm vários usos na engenharia de tecidos e enxertos vasculares. Algumas dessas células também têm demonstrado a capacidade de iniciar processos regenerativos dentro de enxertos. 
Ainda Junqueira \& Carneiro (2004) relatou que o plasma é uma solução aquosa contendo componentes de pequeno peso molecular que correspondem a $10 \%$ de seu volume. As proteínas plasmáticas correspondem a $7 \%$ e os sais inorgânicos, a $0.9 \%$, sendo o restante formado por compostos orgânicos diversos, tais como aminoácidos, vitaminas, hormônios e glicose.

Muitos testes biomoleculares são feitos através de amostras sanguíneas e plasmáticas. Amostras de sangue demonstraram refletir estados patológicos como o Acidente vascular cerebral (AVC), isquêmico e hemorrágico. Entre elas podemos citar como meio de diagnóstico a Proteína C reativa (PCR), P-selectina, homocisteina e Proteína glial fibrilar ácida (GFAP) e como meio de prognóstico glicose, glutamato, D-dímero e fibrogenio (HASSAN et al., 2010).

Ainda, muitos estudos relatam que perante a DP os doentes quando comparados com controles saudáveis apresentaram níveis circulantes sanguíneos aumentados de vários marcadores, como por exemplo: proteina C reativa, (LOOS et al., 2000; BIZARRO et al., 2007), fibrinogênio (KWEIDER et al., 1993; SCHWAHN et al., 2004) e citocinas (NOVAK et al., 2001; GORSKA et al., 2003; IDE et al., 2004).

Um dos componentes importantes para a regulação de mecanismos fisiológicos e patológicos vasculares e sanguíneos é o Óxido Nítrico.

\section{4 Óxido Nítrico}

Óxido Nítrico (NO) foi o primeiro gás conhecido na atuação como mensageiro biológico em mamíferos e identificado como um fator relaxante derivado do endotélio, em 1986 (PALMER et al., 1987). É uma molécula envolvida na regulação 
vascular, homeostase, formação e reabsorção óssea, neurotransmissão e função imunológica (UGAR-ÇANKEL \& OZMERIC, 2006).

Foi descrito tanto em eventos fisiológicos, como regulação do fluxo sanguíneo, mudanças nos níveis durante o ciclo menstrual. Aumentos nas concentrações de estrógeno foram associados com a diminuição de NO, diminuição das concentrações de progesterona foram correlacionados com aumento nas concentrações de NO (MANDHANE et al., 2009). Também foi descrito em condições patológicas como o câncer oral (BAHAR et al., 2006), e na artrite reumatóide, onde as concentrações salivares de NO demonstraram-se baixas (WEINBERG et al., 2006).

No que se diz respeito ao NO no sangue, o aumento do fluxo vascular da microcirculação de um vaso sanguíneo desencadeia um mecanismo através da produção de NO para a dilatação de vasos maiores. O rápido fluxo sanguíneo pelas artérias menores e arteríolas (região microvascular) provocam estresse por cisalhamento das células endoteliais.

Este cisalhamento distorce as células endoteliais na direção do fluxo, provocando um aumento significativo da liberação de NO, que então relaxa os vasos sanguíneos maiores (artérias proximais de tamanho intermediário ou grande). Sem tal resposta, a eficácia do controle local do fluxo sanguíneo seria significantemente reduzida, porque uma parte importante da resistência ao fluxo sanguíneo ocorre nas pequenas artérias próximas a microvascularização (GUYTON \& HALL, 2006).

Além dessas características, ele é um radical livre oxidativo, assim sendo, pode afetar varias reações celulares e funções biológicas (MONCADA \& HIGGS, 1991). Entre elas pode modular e mediar muitas reações imunológicas (LIEW, 1995a), e quando secretado em grandes quantidades pode afetar as funções cardiovasculares. (CALVER et al., 1993). 
Nos últimos anos, tem-se demonstrado que o NO tem um importante papel na defesa do organismo frente a infecções bacterianas, como a DP. Além de atuar em outros sistemas do corpo humano, como já relatado, o NO foi ligado a etiopatogenese da DP (BATISTA et al., 2002) e é expresso em glândulas salivares assim como em seus produtos (LOOMS et al., 2002).

Esse gás biológico é secretado por uma variedade de células do infiltrado inflamatório como neutrófilos e macrófagos (LARFARS et al., 1999 apud OZMERIC, 2004), assim como fibroblastos (DAGHIGH et al., 2002).

Dentre os componentes presentes na saliva, destacam-se os nitritos e o NO.

Este último é gerado a partir de duas vias principais: 1) Nitratos provenientes da dieta são reduzidos por bactérias nitrato redutase positivas. 2) Pela oxidação do NO formado pelas enzimas óxido nítrico sintetase (NOS) (GRISHAM et al., 1995; CAROSSA et al., 2001).

O nitrato é encontrado em altas concentrações em vegetais, como o alface e o espinafre. Este nitrato da dieta é absorvido pelo duodeno, uma vez no sangue ele é transferido para a saliva, onde sua concentração chega a ser 10 vezes maior que no plasma. Uma vez na saliva é rapidamente reduzido na boca em nitrito, pela ação da enzima nitrato redutase expressada por microorganismos orais, em particular aqueles da superfície da língua. Tal processo também pode ocorrer no estômago. Em contato com o meio ácido, o nitrito forma uma mistura de óxidos de nitrogênio, entre eles o ácido nitroso, o qual é instável e irá se decompor em NO e dióxido de nitrogênio (LUNDBERG et al., 1994; ALLAKER et al., 2001).

Segundo Allaker et al. (2001) seus estudos in vitro demonstram que o nitrito presente na saliva, posteriormente convertido em NO, em condições de pH ácido, 
houve o crescimento afetado de microorganismos periodontopatogenicos, sugerindo que o mesmo possa ocorrer in vivo.

No outro mecanismo, o NO é sintetizado por uma família de isoenzimas denominadas óxido nítrico sintetase (NOS) a partir da converção da L-arginina (JENKINS et al., 1995).

A L-arginina é convertida em L-citrulina através da NOS, que é ativada pelo Interferon- $\gamma($ IFN- $\gamma)$.

O Fator de Necrose Tumoral $\alpha$ (TNF $\alpha$ ) desencadeia a reação entre o NOS e a tetrahidrobiopterina, que é um cofator desta enzima, e este NOS atua sob a Larginina, convertendo-a em NO e L-citrulina (Figura 1) (UGAR-ÇANKAL \& OZMERIC, 2006).

O NOS está presente em 3 isoformas, 2 constitutivas e uma induzida pelo estimulo imunológico, sendo elas: eNOS, Óxido Nítrico Sintetase Endotelial; nNOS Óxido Nítrico Sintetase Neuronal e iNOS Óxido Nítrico Sintetase Indutível. Enquanto que o eNOS e nNOS liberam pequenas quantidades de NO, por um curto período de tempo, o iNOS é expresso na resposta ao estimulo pró inflamatório e produz grandes quantidades de NO (UGAR-ÇANKAL \& OZMERIC, 2006).

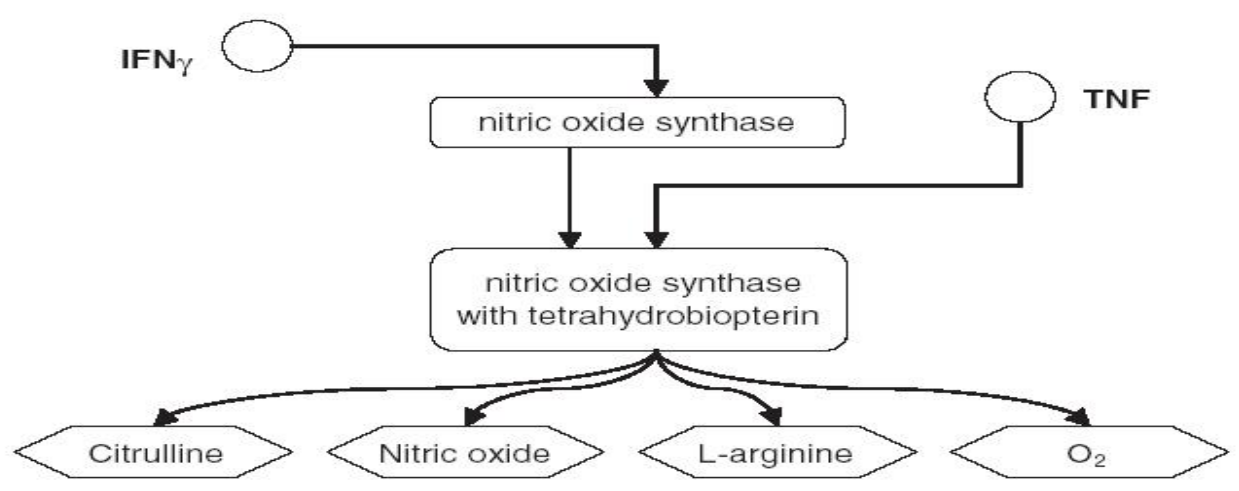

Figura 1: Esquema demonstrativo da cascata reacional de Óxido Nítrico. Retirado do artigo de "A multifaceted molecule, nitric oxide in oral and periodontal disease" Uğar-Çanka, D.; Ozmeric, N., 2006. 
Este radical livre atua tanto beneficamente, como na atividade antimicrobiana e modulação imunológica, quanto prejudicialmente, apresentando citotoxidade aos tecidos adjacentes. (LAURENT et al., 1996; KRONCKE et al., 1997). O NO apresenta propriedades antimicrobianas e é considerada uma importante molécula na defesa contra certas infecções bacterianas (LIEW et al., 1995b).

Tem sido descrito que a produção de NO na cavidade oral relacionada com a DP, se dá via iNOS, uma vez que a resposta inflamatória está ocorrendo. Os fibroblastos, células do infiltrado inflamatório e outras células do periodonto passam a produzir NO via iNOS, o qual faz parte de um mecanismo antibacteriano natural de defesa, na saúde. No entanto, excessivas quantidades desse radical livre podem contribuir para a destruição tecidual na periodontite, de forma patogênica (LOHINAI et al., 1998; KENDALL et al., 2000). O aumento das concentrações de NO produzido nos tecidos periodontais levam a ativação de Metaloproteinas da Matriz (MMPs), assim como uma diminuição das concentrações de seus inibidores, Inibidor Tecidual de Metaloproteinas (TIMPs), e conseqüentemente a destruição periodontal (BRENNAN et al., 2003).

As MMPs são uma família de endopeptidases com atividade dependente de zinco e de cálcio (COUSSENS \& WERB, 1996; KELLY et al., 1998). A função normalmente atribuída nos tecidos as MMPs em pH neutro é degradar os constituintes da matriz extracelular (colágeno, gelatina, laminina, fibronectina, e proteoglicanos) (BIRKEDAL-HAMSEN, 1993). Elas foram descritas tanto em eventos fisiológicos, como desenvolvimento embrionário, morfogênese, reprodução, reabsorção e remodelamento tecidual (GROSS \& LAPIERE,1962), quanto em condições patológicas como a DP, destruição de cartilagem em artrite, ruptura de placa aterosclerótica, reestenose miocárdica, infarto do miocárdio, desenvolvimento 
de aneurismas, metástase tumoral, degeneração macular, entre outras (NAGASE \& WOESSNER, 1999).

Os inibidores endógenos de MMPs - agora conhecido como uma família de quatro Inibidores Teciduais de Metaloproteinases (TIMPs) (GASSON et al., 1985; STETLER-STEVENSON et al., 1992; BREW et al., 2000)- agem formando um complexo 1:1 com o domínio catalítico que contém zinco nas MMPs ( MURPHY et al., 1992; SCHNAPER et al., 1993; KAWAMATA et al., 1995; REYNOLDS, 1996; GUEDEZ et al., 2001).

Muitos trabalhos sugerem que o equilíbrio tecidual entre TIMPs e MMPs seja fundamental para a manutenção da homeostase dos tecidos, resultando na remodelação da matriz extracelular de maneira altamente regulada (GOMEZ et al., 1997; BREW et al., 2000). Em vários processos de doença, as concentrações de MMPs são elevados sem um aumento concomitante dos níveis de TIMPs, resultando na destruição tecidual (DEAN et al., 1989; MURPHY, 1992; REYNOLDS, 1996; NAWROCKI et al., 1997).

O peroxinitrito pode ser produzido por meio da reação de NO com superoxidos $\left(\mathrm{O}_{2}^{-}\right)$, assim como a ativação de peroxidases na presença de nitrito e peróxido de hidrogênio (TURKO \& MURAD, 2002; RADI, 2004). A ativação e inibição, respectivamente das MMPs e dos TIMPs, pode se dar via peroxinitrito (ONOO'). Uma das vias de ativação das MMPs é a oxidação através do peroxinitrito (OKAMOTO et al., 2001).

Donnini et al. (2008) estudou se uma forma especifica de TIMP (TIMP-4) pode ser inativado pelo peroxinitrito e ainda se pode afetar o balanço entre este mesmo inibidor e sua respectiva metaloproteina. Este estudo concluiu que o peroxinitrito pode ter atividade inibitória frente aos TIMPs. 
Vários trabalhos da literatura demonstram que o NO e a iNOS estão aumentados na DP em comparação com controles saudáveis, tanto nas concentrações salivares quanto em amostras de biópsias gengivais (LOHINAI et al., 1998; MATEJKA et al., 1998; GULLU et al., 2005; REHER et al., 2007; PARWANI et al., 2012).

No entanto, Aurer et al. (2001) relatou encontrar concentrações salivares de NO diminuídos na doença periodontal adulta e agressiva. Este estudo está em contraste com a vasta literatura que descreve o aumento das concentrações salivares.

Um dos inibidores da produção de NO é a arginase, a qual está presente no fígado e também em tecidos não hepáticos como as glândulas salivares. Esta enzima (quinta enzima degradadora da Arginina em Ortidina e Uréia, no Ciclo da Uréia), a qual pode competir com o substrato comum ao NOS (L-arginina) e desta maneira inibir a produção de NO (OZER et al., 2011).

No que tange as concentrações de arginase na saliva de pacientes periodontalmente comprometidos, têm-se demonstrado que estes apresentam altas quantidades desta enzima em relação aos pacientes saudáveis. O aumento da atividade dessa em pacientes periodontais talvez cause a diminuição da síntese de NO, levando assim, a diminuição das propriedades antibacterianas e o dano tecidual, via suscetibilidade a infecção bacteriana (OZMERIÇ et al., 2000).

Em suma, diferentes concentrações de NO salivar e tecidual são o limiar entre a saúde periodontal e a doença. Altas quantidades levam ao dano tecidual, via citotoxidade e concentrações basais a saúde, através das propriedades antimicrobianas. Em contrapartida, uma alta atividade a arginase também resulta em DP, através anulação da propriedade antimicrobiana do NO, na saúde oral. 
Atualmente, a ciência tem impulsionado novas técnicas, uma delas são os biomarcadores. Eles otimizam o diagnóstico, os custos e o tornam o processo mais dinâmico (FARNAUD et al., 2010).

Assim, a coleta de saliva é uma alternativa não invasiva e rápida, não sendo requisitada a utilização de material e mão de obra especializada. Portanto, a utilização da saliva para a detecção antecipada de doenças bucais e sistêmicas é um método relevante (LAWRENCE, 2002).

Conhecer as concentrações de NO nos diferentes tipos de saliva, no sangue total, eritrócitos e plasma é muito importante, uma vez que a partir dos resultados obtidos na saliva poderão ser feitas inferências sobre os efeitos do NO ou sua falta no desenvolvimento da doença periodontal, enquanto possivelmente os resultados de NO no sangue total possam subsidiar outros dados acerca da inflamação sistêmica já caracterizada neste grupo de pacientes (MARCACCINI et al., 2009a; MARCACCINI et al., 2009b).

Neste estudo propomos estudar as concentrações de NO na saliva total, saliva sumandibular/sublingual, parotídea, no sangue total, eritrócitos e plasma de pacientes controle e pacientes com doença periodontal crônica, com coletas antes e 3 meses após o tratamento periodontal não cirúrgico. 


\section{HIPÓTESE}

De acordo com a literatura, menores concentrações de nitrito foram encontradas em pacientes com doença periodontal em comparação com controles, assim nossa hipótese a ser testada com dados de nosso grupo de pacientes é:

1- Que as concentrações de nitrito sejam menores na saliva total de indivíduos com doença periodontal e que estas aumentem após o tratamento periodontal.

De acordo com a literatura, o NO do plasma refletiria as concentrações de nitrito produzidos pelas bactérias comensais da boca, uma vez que este nitrito no estômago seria transformado em NO e este seja absorvido. Ou seja, as concentrações no sangue total refletiriam as concentrações salivares, em concentrações mil vezes menores. Assim, nossa hipótese seria:

2- Que haveria o mesmo perfil de variação nas concentrações de nitrito no sangue total, eritróticos e plasma vista na saliva total. 
OBJETIVOS 


\section{OBJETIVOS}

1) Medir as concentrações de nitrito na saliva total, saliva submandibular/sublingual, saliva parotídea, sangue total, eritrócitos e plasma de indivíduos com doença periodontal e controles, antes e depois do tratamento não cirúrgico;

2) Comparar as concentrações de nitrito na saliva total e no sangue total e eritrócitos.

3) Determinar o efeito do tratamento nos parâmetros estudados. 


\section{MATERIAL E MÉTODO}

\subsection{Materiais}

\subsubsection{Materiais utilizados na etapa clínica}

-Soro fisiológico $0.9 \%$

-Gazes esterilizadas

-Cuba de inox, Fava Millenium

-Conjunto de curetas Gracey (05/06, 07/08, 11/12, 13/14, mini five 11/12, mini five 13/14), Hu Friedy

-Cavitron, Dentsply

-Anestésico tópico gel, Benzotop (Benzocaina 200mg/g), DFL

-Mepiadre (cloridrato de mepivacaína 2\%, epinefrina 1:100.000), DFL

-Mepisv (cloridrato de mepivacaína 3\%), DFL

-Florida Probe System, Florida Probe

-Cânula de seringa Luer Lock

-Seringa Luer Lock $10 \mathrm{ml}$, Ruthe

-Moldeiras perfuradas

-Gesso Pedra tipo III

-Placas de acetato

-Alginato Avagel, Dentsply

-Fimes radiográficos periapicas, Kodac

-Posicionador Radiográfico Indicator, Indusbello

-Taças profiláticas 
-Pasta profilática, Herjos

-Contra- ângulo INTRAmatic 2068, KaVo

-Vacutainer com heparina de sódio, Becton-Dickison

-Agulhas descartáveis 3, Becton-Dickison

\subsubsection{Soluções utilizadas na etapa laboratorial}

$-0.8 \mathrm{M}$ de Ferro Cianeto $+10 \%$ de NP40

-Metanol absoluto

- Água MilliQ

-Solução de tri-iodeto ácido (2 g de iodeto de potássio e 1,3g de iodo dissolvido em $40 \mathrm{ml}$ de água com $140 \mathrm{ml}$ de ácido acético)

-Soluções com diferentes concentrações de $\mathrm{NaNO}_{2}$, para a curva de calibração.

\subsubsection{Equipamentos utilizados na etapa laboratorial}

- Nitric Oxide Analyzer Sievers ${ }^{\circledR}\left(\mathrm{NOA}^{\mathrm{TM}}\right)$ - modelo 280i

- Seringa de $20 \mu \mathrm{L}$ de capacidade

- Tubos eppendorf

- Pipetas automáticas de volumes variados LabMate.

- Ponteiras variadas, Axygen.

- Vidraria (béquer, proveta, balões volumétricos, funil)

- Papel de filtro.

- Estante para tubos.

-Centrifuga refrigerada. 


\subsubsection{Programas de aquisição de dados}

-FP32 Perio Software, Florida Probe

-Graphpad Prism 5.0 for Windows (Software Mackiev, USA)

\subsection{Métodos}

\subsubsection{Seleção dos pacientes}

Este estudo foi aprovado pelo Comitê de Ética em Pesquisa da Faculdade de Odontologia de Ribeirão Preto, da Universidade de São Paulo (FORP-USP) sob o número de protocolo 0063.0.138.000-05. Os pacientes foram triados na Clínica de Periodontia, Departamento de Cirurgia Buco-Maxilo-Facial e Periodontia da Faculdade de Odontologia de Ribeirão Preto/USP e informados por escrito, bem como verbalmente sobre os propósitos do estudo, a necessidade de tratamento, possibilidade de realização de fotos não identificadas e o comprometimento com a assiduidade. Todas as dúvidas pertinentes ao estudo e ao tratamento foram esclarecidas. Foi assinado o termo de consentimento livre e esclarecido (TCLE), por ambas as partes, antes da inclusão dos indivíduos na pesquisa.

A seleção dos pacientes, diagnóstico e tratamento da DP foram realizados de acordo com (MARCACCINI et al., 2009a; NOVAES et al., 2009). Todos os pacientes foram examinados e tratados por um único periodontista.

Foram excluídos indivíduos que tivessem recebido qualquer cirurgia periodontal nos últimos seis meses, ou fizeram uso de antibióticos, antiinflamatórios não esteroidais, esteróides, imunossupressores, anticoagulantes ou anti-hiperlipidêmicos nesse mesmo 
período. Também foram critérios de exclusão: doenças crônicas, doenças infecciosas, gravidez, lactação, fumantes e ex-fumantes (que pararam de fumar há menos de 10 anos).

Os critérios de inclusão para os pacientes deste estudo são: ter entre 35 a 55 anos e possuíam no mínimo 20 dentes sem comprometimento endodôntico.

Os critérios inclusão no grupo de pacientes com DP (doença periodontal) (DPA- doentes antes do tratamento e DPD- doentes depois do tratamento) era de que tivessem pelo menos 2 dentes com sítios de sondagem $\geq 5 \mathrm{~mm}$, com perda de inserção clínica $\geq 6 \mathrm{~mm}$ e evidências de perda óssea alveolar observáveis radiograficamente.

Aqueles indivíduos que não se encaixavam no grupo com doença periodontal, ou seja, apresentavam saúde periodontal foram incluídos no grupo controle (CAcontrole antes do tratamento e CD- controle depois do tratamento).

Os seguintes parâmetros clínicos foram analisados: de número de dentes, profundidade de sondagem (PD) (distância do fundo do sulco até a margem gengival), nível de inserção clínica (CAL) (distância entre a margem gengival e a junção cemento esmalte) e sangramento a sondagem (BOP) (determinado pela presença +, ou ausência - de sangramento observado, durante 30 segundos, após a inserção da sonda na bolsa periodontal) e sítios com profundidade de sondagem maior que $4 \mathrm{~mm}$ de todas as seis faces de cada dente. As medidas de PD e CAL e sítios maiores que $4 \mathrm{~mm}$ foram aferidas antes e após a terapia periodontal utilizando equipamento de sondagem computadorizada (Florida Probe) e uma placa de acetato, confeccionada a partir da moldagem de cada paciente. Todos estes procedimentos foram realizados por um único periodontista. 
Todos os indivíduos selecionados para este estudo receberam instruções de higiene bucal e profilaxia supragengival, e foram re-examinados a cada 15 dias, durante 3 meses. As coletas de sangue e saliva total expectorada (SAT) foram realizadas no início da pesquisa (baseline) e também após 3 meses.

Os pacientes selecionados para grupo DP foram submetidos ao tratamento periodontal não cirúrgico (básico), que consistiu em quatro sessões de raspagem e alisamento radicular, cada uma com uma hora de duração. Todas as sessões foram realizadas em um período máximo quatro semanas.

\subsubsection{Coleta da saliva}

A saliva total expectorada (SAT) foi coletada por expectoração após os pacientes mastigarem uma pequena folha de parafilme (Parafilm), sob $12 \mathrm{~h}$ de jejum. As amostras foram submetidas a centrifugação branda (15 minutos a 2000 rpm a $4^{\circ} \mathrm{C}$ ) para separar células sem lisá-las, até $1 \mathrm{~h}$ após sua coleta. Em seguida, os sobrenadantes foram novamente centrifugados (10 minutos a $12.000 \mathrm{~g}, 4^{\circ} \mathrm{C}$ ) para a separação de partículas, proteínas insolúveis e microrganismos que ainda estivessem em suspensão.

\subsubsection{Coleta sanguínea}

Os pacientes foram aconselhados a fazer jejum de 12 horas antes da coleta de sangue por punção venosa. A colheita foi realizada com dispositivos Vacutainer (Becton-Dickison) contendo heparina como anticoagulante, utilizando dois tubos. No tubo de sangue total foi adicionado solução estabilizadora (0.8M de Ferro Cianeto + 
$10 \%$ de NP40) na proporção de 1:30 do volume da amostra. No segundo tubo foi realizada a centrifugação a fim de dividir o sangue em plasma e células vermelhas. Imediatamente após a centrifugação foi adicionado a solução estabilizadora as alíquotas de plasma e eritrócitos na proporção de 1:30 do volume da amostra. Então realizou-se a desproteinização do tubo com sangue total e também da amostra de eritrócitos, previamente separados do plasma.

Para a desproteinização foram adicionados metanol refrigerado $\left(0^{\circ} \mathrm{C}\right)$ as amostras (sangue total e eritrócitos), na proporção de 1:1. Realizou-se a centrifugação para desproteinizar as amostras (7 minutos, a 14.000 rpm) e, em seguida, colocados em banho de gelo até o termino da divisão em alíquotas em microtubos (eppendorfs). As amostras de eritrócitos, sangue total desproteinizadas e plasma foram armazenadas em freezer $-80^{\circ} \mathrm{C}$ até a sua utilização no aparelho de aferição de NO por quimiluminescência.

\subsubsection{Ensaio de NO por quimiluminescência}

Através do aparelho Nitric Oxide Analyzer Sievers ${ }^{\circledR}\left(\mathrm{NOA}^{\mathrm{TM}}\right)$ - modelo 280i, da Faculdade de Medicina de Ribeirão Preto- USP foi feita a aferição das concentrações de NO nas amostras.

O aparelho é composto de uma câmara de vidro selada, onde é injetado certa quantidade de amostra (no caso de amostras sanguíneas $300 \mu \mathrm{L}$, nas amostras salivar total $100 \mu \mathrm{L}$ na concentração de $5 \%$, no caso da parotídea e submandibular/sublingual 100uL na concentração de 50\%) em contato com $8 \mathrm{ml}$ de solução de tri-iodeto acidificado ( $2 \mathrm{~g}$ de iodeto de potássio e $1,3 \mathrm{~g}$ de iodo dissolvido em $40 \mathrm{ml}$ de água com $140 \mathrm{ml}$ de ácido acético). O gás produzido pela reação do 
nitrito com a solução ácida de iodeto é o NO, o qual é levado por um fluxo continuo de gás nitrogênio até outra câmara para a reação com o ozônio.

A detecção do NO no aparelho é baseada na reação de fase gasosa de NO com ozônio, através da seguinte reação:

$$
\begin{gathered}
\mathrm{NO}+\mathrm{O}_{3} \longrightarrow \mathrm{NO}_{2}{ }^{*}+\mathrm{O}_{2} \\
\mathrm{NO}_{2}{ }^{*} \longrightarrow \mathrm{NO}_{2}+\mathrm{hv}
\end{gathered}
$$

Reação 1- Reação entre o óxido nítrico e o ozônio. $\mathrm{O}_{3}$, ozônio; $\mathrm{NO}$, óxido nítrico; $\mathrm{NO}_{2}$, dióxido de nitrogênio; $\mathrm{H}^{+}$íon hidrogênio, hv, excitação luminosa.

NO reage com o ozônio o que gera dióxido de nitrogênio em estado excitado. Após o retorno ao estado fundamental, o dióxido de nitrogênio emite luz, a qual e detectada pelo aparelho, em milivolts (mV). (BRYAN \& GRISHAM, 2007).

Para a conversão medida pelo aparelho em $\mathrm{mV}$ em concentrações de $\mu \mathrm{M}$ ou $\mathrm{nM}$ foi confeccionada uma curva de calibração com valores medidos em triplicata. A média da área dos picos obtidos nos gráficos de calibração foi usada para a conversão nos níveis de concentração plasmática e salivar de NO.

Foram utilizadas as seguintes soluções de nitrito de sódio $\left(\mathrm{NaNO}_{2}\right)$, nas seguintes concentrações, para a confecção da curva de calibração do aparelho: $0.5 \mu \mathrm{M}, 1 \mu \mathrm{M}, 5 \mu \mathrm{M}, 10 \mu \mathrm{M}, 20 \mu \mathrm{M}, 50 \mu \mathrm{M}, 100 \mu \mathrm{M}$. Cada via recebeu um volume de 15 $\mu \mathrm{L}$ de solução. Importante salientarmos que os instrumentos estavam livres de nitrato e nitrito, e foram constantemente lavados a cada procedimento com água MilliQ e limpos com material descontaminado. Desta forma, obtivemos as concentrações salivares e sanguíneas de NO. 


\subsubsection{Análise Estatística}

As concentrações de óxido nítrico na Saliva total (SAT), Saliva Submandibular/sublingual (SSUB), Saliva Parotídea (SP), Sangue Total (SNT), Eritrócitos (ER) e Plasma (PL) tiveram seus valores separados em dois grupos e dois períodos de acordo com a classificação do paciente, assim como os parâmetros clinicos (BOP; CAL; PD; Sítios maiores que 4mm):

Sangramento a Sondagem (BOP)- Doença Periodontal antes do tratamento não cirúrgico (DPA) ( $n=23)$, Doença Periodontal após o tratamento (DPD) ( $n=23)$, controle no início do estudo (baseline) $(C A)(n=17)$ e controle após 3 meses (CD) ( $n=17)$.

Nível Clinico de Inserção (CAL)- Doença Periodontal antes do tratamento não cirúrgico (DPA) $(n=23)$, Doença Periodontal após o tratamento (DPD) $(n=23)$, controle no início do estudo (baseline) (CA) ( $n=17)$ e controle após 3 meses (CD) ( $n=17)$.

Profundidade de Sondagem (PD)- Doença Periodontal antes do tratamento não cirúrgico (DPA) ( $n=23)$, Doença Periodontal após o tratamento (DPD) ( $n=23)$, controle no início do estudo (baseline) (CA) ( $n=17)$ e controle após 3 meses (CD) ( $n=17)$.

Sítios maiores que $4 \mathrm{~mm}$ - Doença Periodontal antes do tratamento não cirúrgico (DPA) $(n=23)$, Doença Periodontal após o tratamento (DPD) $(n=23)$, controle no início do estudo (baseline) (CA) $(n=17)$ e controle após 3 meses $(C D)(n=17)$.

Saliva Total (SAT)- Doença Periodontal antes do tratamento não cirúrgico (DPA) $(n=22)$, Doença Periodontal após o tratamento (DPD) $(n=22)$, controle no início do estudo (baseline) (CA) ( $n=19)$ e controle após 3 meses (CD) $(n=15)$.

Saliva Submandibular/sublingual (SSUB)- Doença Periodontal antes do tratamento não cirúrgico (DPA) $(n=19)$, Doença Periodontal após o tratamento (DPD) $(n=23)$, controle no início do estudo (baseline) $(C A)(n=17)$ e controle após 3 meses $(C D)(n=13)$. 
Saliva Parotídea (SP)- Doença Periodontal antes do tratamento não cirúrgico (DPA) $(n=25)$, Doença Periodontal após o tratamento (DPD) $(n=24)$, controle no início do estudo (baseline) (CA) ( $n=15)$ e controle após 3 meses (CD) $(n=12)$.

Sangue Total (SNT)- Doença Periodontal antes do tratamento não cirúrgico (DPA) $(n=24)$, Doença Periodontal após o tratamento (DPD) $(n=23)$, controle no início do estudo (baseline) (CA) $(n=16)$ e controle após 3 meses $(C D)(n=8)$.

Eritrócitos (ER)- Doença Periodontal antes do tratamento não cirúrgico (DPA) ( $n=21)$, Doença Periodontal após o tratamento (DPD) $(n=19)$, controle no início do estudo (baseline) (CA) $(n=11)$ e controle após 3 meses $(C D)(n=9)$.

Plasma (PL)- Doença Periodontal antes do tratamento não cirúrgico (DPA) (n $=26$ ), Doença Periodontal após o tratamento (DPD) $(n=22)$, controle no início do estudo (baseline) (CA) $(n=17)$ e controle após 3 meses $(C D)(n=9)$.

Foi utilizado o teste $t$ pareado para comparar as médias quando estas eram do mesmo grupo (por exemplo, controles, ou doentes), seguindo uma distribuição normal. Foi utilizado o teste t não pareado quando comparado às médias de grupos diferentes (por exemplo, doentes com os controles), seguindo distribuição normal. Ainda foi utilizado o teste Wilcoxon quando as amostras eram do mesmo grupo e o grupo não apresentava uma distribuição normal e Mann-Whitney quando as amostras eram de grupos diferentes e não seguiam distribuição normal. Foram consideradas diferenças estatisticamente significantes quando $p<0,05$. Serão detalhados todos os valores de $p$ na seção seguinte. Ainda nesta mesma, subseqüente seção, será apresentados os valores da média ou mediana de cada grupo, o desvio padrão e os valores dos percentis de 25\% (Q1) e 75\% (Q3). 
RESULTADOS 


\section{RESULTADOS}

\subsection{Resultados Clínicos}

\subsubsection{Sangramento a sondagem}

O sangramento a sondagem é determinado pela presença + , ou ausência - de sangramento observado, durante 30 segundos, após a inserção da sonda na bolsa periodontal. $\mathrm{Na}$ análise estatística entre os grupos, todos apresentaram distribuição normal, portanto foram utilizados os teste t pareado (CA versus CD, DPA versus DPD), e teste t não pareado (CA versus PDA). Os valores da média e do desvio padrão foram, CA $(16,12 \pm 8,2), \mathrm{CD}(10,59 \pm 4,43), \mathrm{DPA}(43,7 \pm 20,18)$, DPD $(16,22 \pm 6,48)$. Ainda, todos os grupos tem diferenças estatisticamente significantes, CA versus CD, $p=0.0005$, DPA versus DPD, $p<0,0001$, CA versus PDA $p<0,0001$. Conforme podemos notar na Figura 2.

\section{Dados Clínicos}

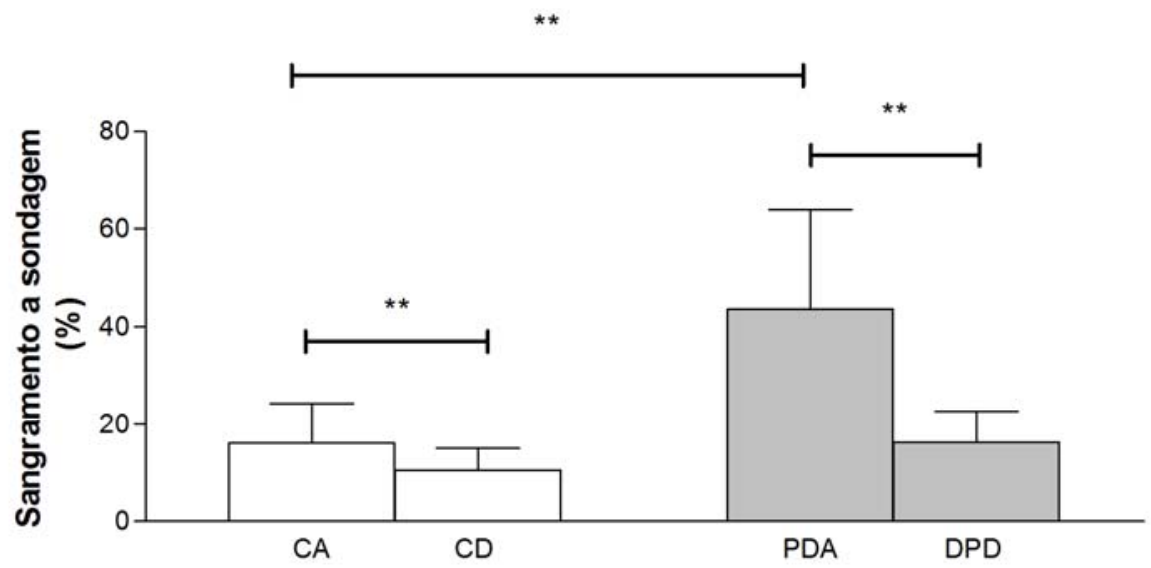

GRUPOS

Figura 2- Presença ou ausência de sangramento a sondagem após 30 segundos de inserção da sonda. Houve menor sangramento detectado no grupo DP após o tratamento em relação ao grupo DP antes do tratamento. Também é observada uma diminuição quando se compara o grupo controle antes do tratamento e depois do tratamento. CA: pacientes controle no inicio do estudo; CD: pacientes controle 3 meses após o estudo; PDA: pacientes com doença periodontal no inicio do estudo; PDP: pacientes com doença periodontal tratada após 3 meses de estudo, ${ }^{* *} p<0,001$. 


\subsubsection{Nível Clínico de Inserção}

É caracterizado como a distância entre a margem gengival e a junção cemento esmalte.

Na Figura 3, observamos os níveis clínicos de inserção da sonda periodontal. Os grupos que demonstraram distribuição normal foram: DPA e DPD. Os grupos que demonstraram distribuição não normal foram: CA e CD. Portanto, os teste Wilcoxon, teste t pareado e Mann-Whitney teste foram empregados. Notamos uma diminuição das médias quando comparado os grupos CA $(2,09 \pm 0,39)$ e CD $(2,00 \pm 0,34)$, havendo diferença estatisticamente significante $(p<0,01)$. Podemos também inferir que houve diferença estatisticamente significante entre os grupos PDA $(2,86 \pm 0,77)$ e PDP $(2,46 \pm$ $0,56)$ com $(p<0,0001)$. Da mesma forma quando comparamos os valores de CA com DPA encontramos diferença estatisticamente significante $(p<0,0002)$.

\section{Dados Clínicos}

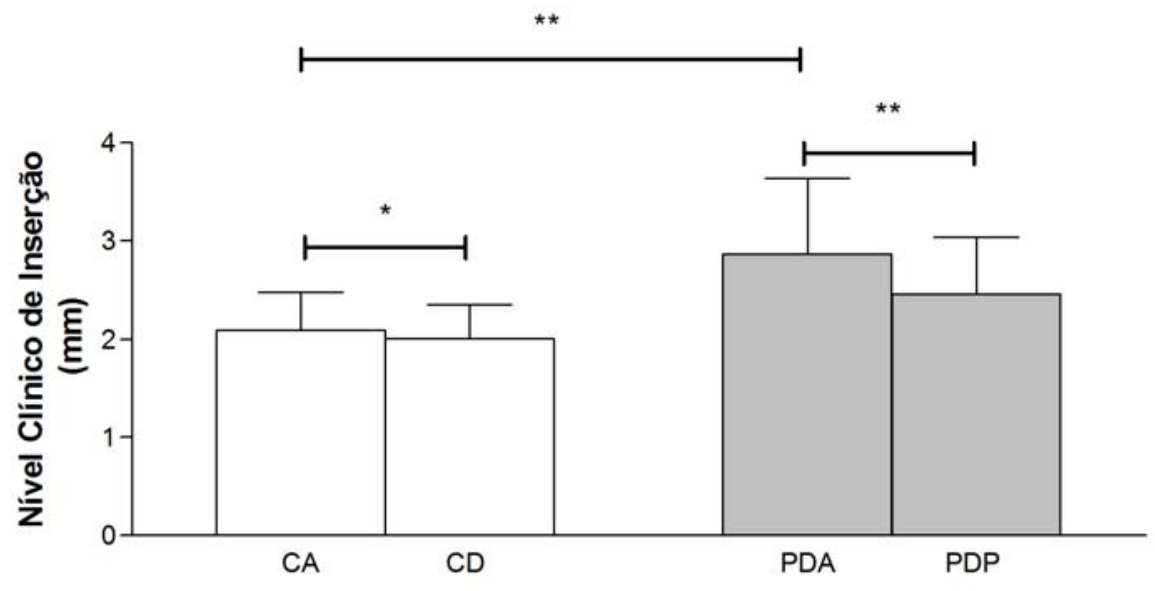

\section{GRUPOS}

Figura 3- Nível clinico de inserção, caracterizado pela distância em milímetros (mm) entre a margem gengival e a junção cemento esmalte. Houve diferença estatisticamente significante quando comparado os controles antes e após o tratamento (CA versus CD), pacientes com DP antes e após o tratamento (PDA versus PDP) e o controle antes do tratamento com a DP antes do tratamento (CA versus DPA). CA : pacientes controle no inicio do estudo; CD: pacientes controle 3 meses após 0 estudo; PDA: pacientes com doença periodontal no inicio do estudo; PDP: pacientes com doença periodontal tratada após 3 meses de estudo. A altura das colunas indicam as médias e as barras 0 desvio padrão, * $p<0,05 ;{ }^{* \star} p<0,001$ 


\subsubsection{Profundidade de Sondagem}

Caracteriza-se pela distância do fundo do sulco até a margem gengival.

Na Figura 4, notamos que não houve diferença estatisticamente significante entre as médias dos grupos CA $(1,51 \pm 0,17)$ e CD $(1,49 \pm 0,13)$, com $p=0,31$. Entretanto, notamos diferenças significativas entre os grupos DPA $(2,31 \pm 0,46)$ e DPD $(1,92 \pm 0,28), p<0,0001$, assim como CA $(1,51 \pm 0,17)$ e DPA $(2,31 \pm 0,46)$, $p<0,0001$. Os grupos apresentam distribuição normal, dessa forma foram empregados o teste $t$ pareado entre os grupos CA versus CD, PDA versus PDP e teste não pareado entre os grupos CA versus CD.

\section{Dados Clínicos}

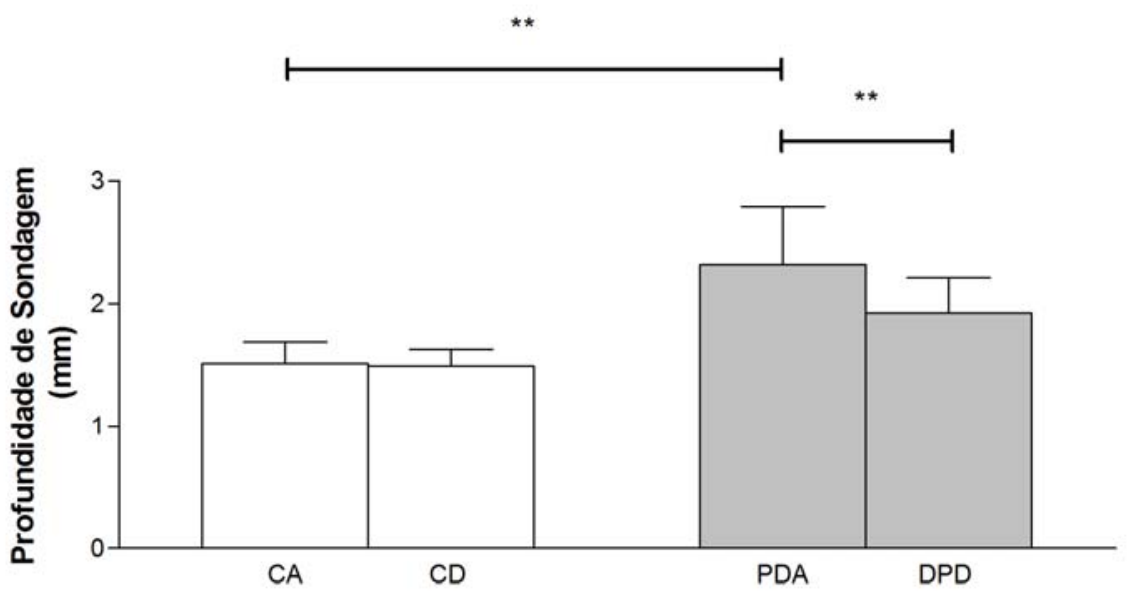

GRUPOS

Figura 4- Profundidade de sondagem é a distancia em milímetros $(\mathrm{mm})$ entre o fundo do sulco gengival e a margem gengival. Notamos que houve diferença estatisticamente significante quando comparado os pacientes com DP antes e após o tratamento (PDA versus PDP) e o controle antes do tratamento com a DP antes do tratamento (CA versus DPA). CA: pacientes controle no inicio do estudo; CD: pacientes controle 3 meses após o estudo; PDA: pacientes com doença periodontal no inicio do estudo; PDP: pacientes com doença periodontal tratada após 3 meses de estudo. A altura das colunas indicam as médias e as barras o desvio padrão, ${ }^{*} p<0,001$. 


\subsubsection{Sítios com profundidade $>4 \mathrm{~mm}$}

São sítios que apresentam profundidade de sondagem maior que 4 milímetros, o que torna um limiar entre os sítios saudáveis e o com DP atuante.

Na Figura 5 os grupos CA $(0,02 \pm 0,37)$ e CD $(0,0 \pm 0,0)$ não apresentam medias estatisticamente diferentes, $p=0,08$. Já os grupos DPA $(9,79 \pm 18,03)$ e DPD $(5,02 \pm 8,97)$ quando comparados apresentam diferenças estatisticamente significantes, $p<0,0001$. Os grupos CA media $(0,02 \pm 0,37)$ versus DPA $(9,79 \pm$ $18,03)$ também apresentam diferenças estatisticamente significantes, $p<0,0001$. Os grupos CA e DPA não apresentam distribuição normal, o grupo CD apresentou valores nulos. Já o grupo DPD apresentou distribuição normal. Desta forma foram empregados os teste $\mathrm{t}$ pareado, nos grupos CA versus CD, teste Wilcoxon, nos grupos DPA versus DPD e Mann-Whitney nos grupos CA versus PDA.

\section{Dados Clínicos}

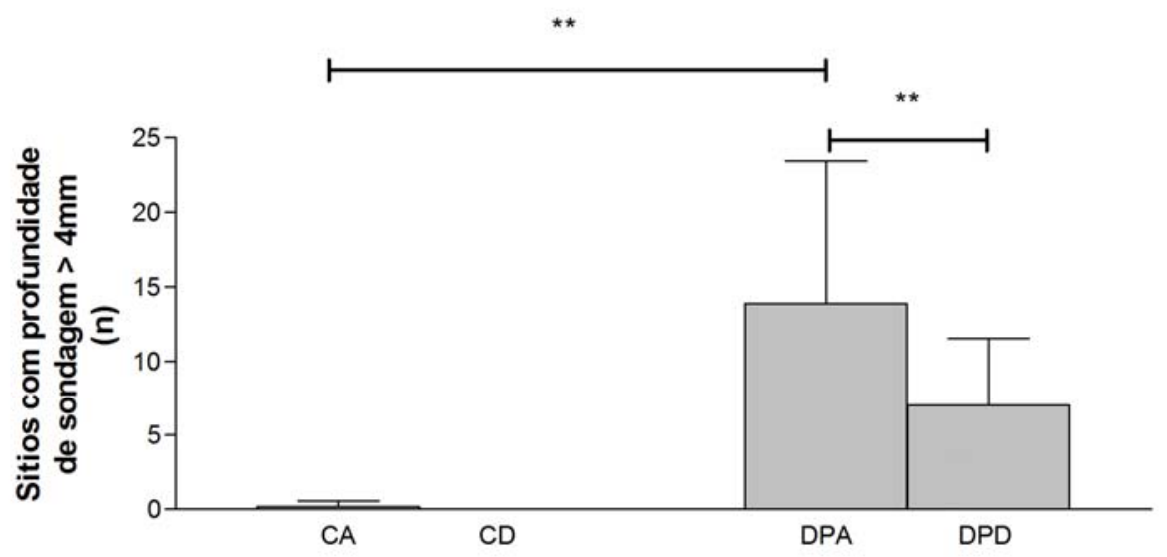

GRUPOS

Figura 5- Sítios com profundidade de sondagem maior que $4 \mathrm{~mm}$. Observamos que não houve diferença estatisticamente significantes entre os grupos $C A$ e $C D$, havendo diferença entre os grupos DPA e DPD, bem como CA e DPA. CA: pacientes controle no inicio do estudo; CD: pacientes controle 3 meses após o estudo; PDA: pacientes com doença periodontal no inicio do estudo; PDP: pacientes com doença periodontal tratada após 3 meses de estudo. A altura das colunas indica a média e a barra o desvio padrão, ${ }^{* *} p<0,001$. 


\subsection{Concentrações salivares de nitrito}

\subsubsection{Concentrações de nitrito na saliva total}

Os resultados da Figura 6 revelam que as concentrações de nitrito salivar total apresentam-se com valores medianos próximos no início do estudo DPA= 0,44 (Q1= 0,26/ Q3 = 0,81) quando comparados com o grupo após tratamento DPD, mediana= 0,38 $(\mathrm{Q} 1=0,22 / \mathrm{Q} 3=0,69)$, não havendo diferença estatisticamente significante $p=0.41$. Já quando analisamos os valores de CA, mediana=0,69 $(Q 1=0,46 / Q 3=1,44)$ e DPA, mediana $=0,44(\mathrm{Q} 1=0,26 / \mathrm{Q} 3=0,81)$, encontramos diferença estatisticamente significante $p=0,04$. Quando comparamos os grupos controle CA, mediana= 0,69 $(\mathrm{Q} 1=$ 0,46/Q3 =1,44) versus $C D$, mediana= 0,55 $(Q 1=0,39 / Q 3=1,55)$, não há diferença estatística, $p=0,84$. Todos os grupos (CA; CD; DPA; DPD), apresentaram distribuição não normal, assim sendo foram empregados os teste Wilcoxon e Mann-Whitney.

\section{Saliva Total}

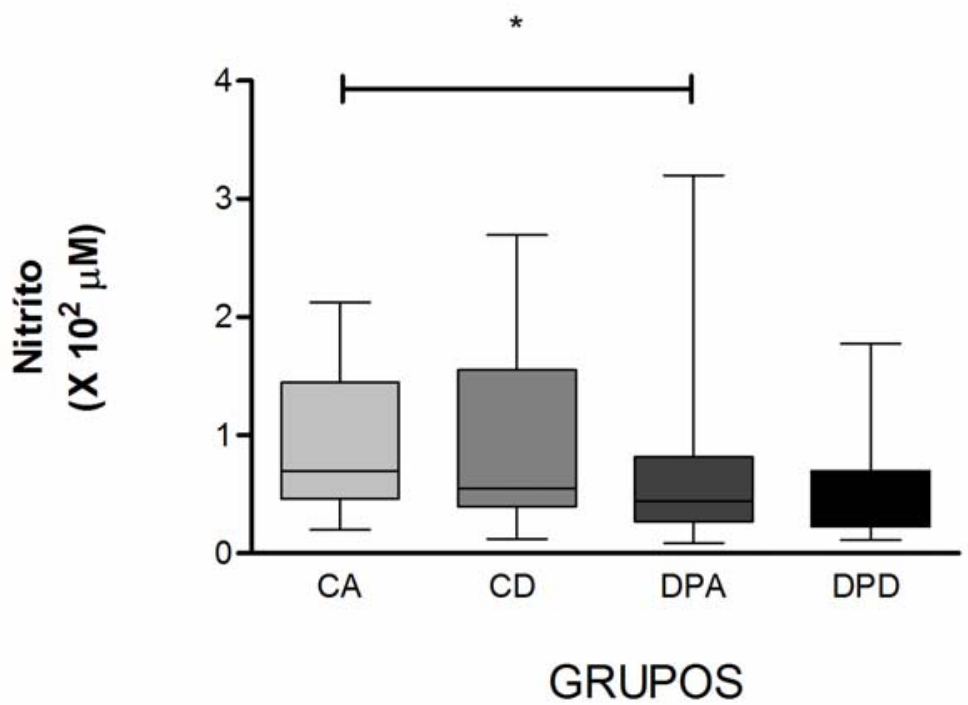

Figura 6- Gráfico que representa as concentrações salivares totais de nitrito (mediana e percentis) de pacientes antes e depois do tratamento periodontal básico, assim como os controles, antes e depois do tratamento. Não há diferenças estatisticamente significantes entre os grupos CA versus CD, DPA versus DPD. CA : pacientes controle no inicio do estudo; CD: pacientes controle 3 meses após o estudo; PDA: pacientes com doença periodontal no inicio do estudo; PDP: pacientes com doença periodontal tratada após 3 meses de estudo, ${ }^{*} p<0,05$. 


\subsubsection{Concentrações de nitrito na saliva parotídea}

Na Figura 7, podemos inferir que não houve diferenças significantes entre as médias dos grupos CA $(0,58 \pm 0,32)$ versus $\operatorname{CD}(0,69 \pm 0,33)$ com $p=0,5$, DPA $(0,69$ $\pm 0,36)$ versus DPD $(0,85 \pm 0,58)$ com $p=0,14$ e CA $(0,58 \pm 0,32)$ versus DPA $(0,69$ $\pm 0,36)$ com $p=0,33$. Os grupos CA, CD, DPA apresentaram distribuição normal, o grupo DPD não apresentou distribuição normal. Sendo assim, foram empregados os teste $\mathrm{t}$ pareado, Wilcoxon teste e teste $\mathrm{t}$ não pareado, respectivamente para $\mathrm{CA}$ versus CD, DPA versus DPD, e CA versus DPA.

\section{Saliva Parótida}

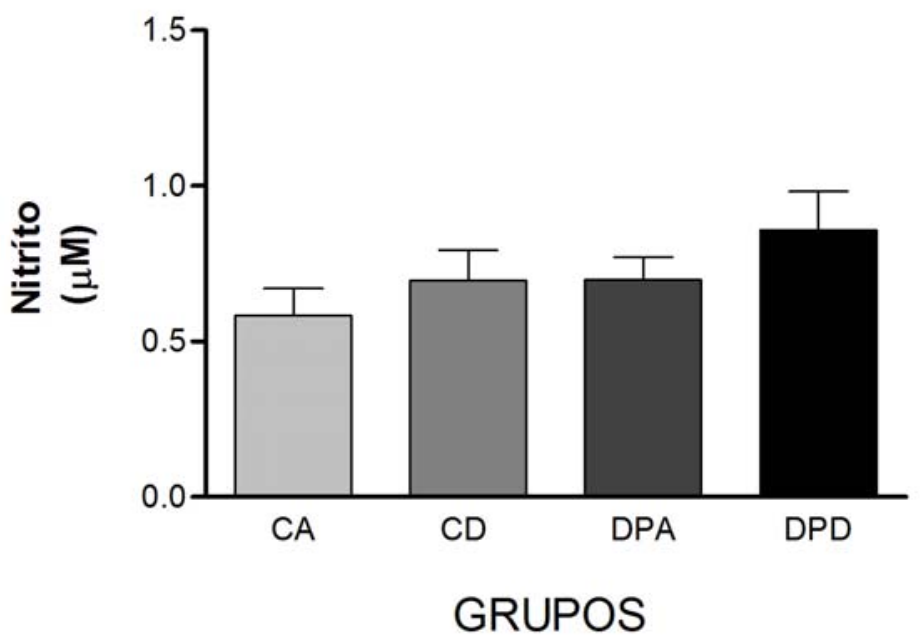

Figura 7- Gráfico que representa as concentrações salivares parotídeas de nitrito (média \pm desvio padrão) de pacientes antes e depois do tratamento periodontal básico, assim como os controles antes e após o tratamento. Não há diferenças estatisticamente significantes entre os grupos CA versus CD, DPA versus DPD, CA versus DPA. CA: pacientes controle no inicio do estudo; CD: pacientes controle 3 meses após o estudo; PDA: pacientes com doença periodontal no inicio do estudo; PDP: pacientes com doença periodontal tratada após 3 meses de estudo. 


\subsubsection{Concentrações de nitrito na saliva submandibular e sublingual}

A Figura 8 demonstra as concentrações de nitrito nas amostras de saliva submandibular e sublingual, notamos que não houve diferenças significantes entre os grupos CA, mediana=1,86 $(\mathrm{Q} 1=0,61 / \mathrm{Q} 3=4,59)$ versus $C D$, mediana= 2,64 $(\mathrm{Q} 1=$ 1,82/ $\mathrm{Q} 3=4,37)$, com $p=0,41 . \mathrm{DPA}$, mediana $=2,37(\mathrm{Q} 1=0,47 / \mathrm{Q} 3=4,79)$ versus $\mathrm{DPD}$ mediana $=2,69(\mathrm{Q} 1=1,69 / \mathrm{Q} 3=3,43)$ com $p=0,57$ e CA mediana $=1,86(\mathrm{Q} 1=$ $0,61 / \mathrm{Q} 3=4,59)$ versus DPA mediana $=2,37(\mathrm{Q} 1=0,47 / \mathrm{Q} 3=4,79)$ com $p=0,97$. Os grupos CD, DPA e DPD apresentam distribuição normal, no entanto o grupo CA apresentou distribuição não normal. Dessa forma foram empregados os testes Wilcoson teste, teste t pareado, Mann-Whitney teste.

\section{Saliva Sub}

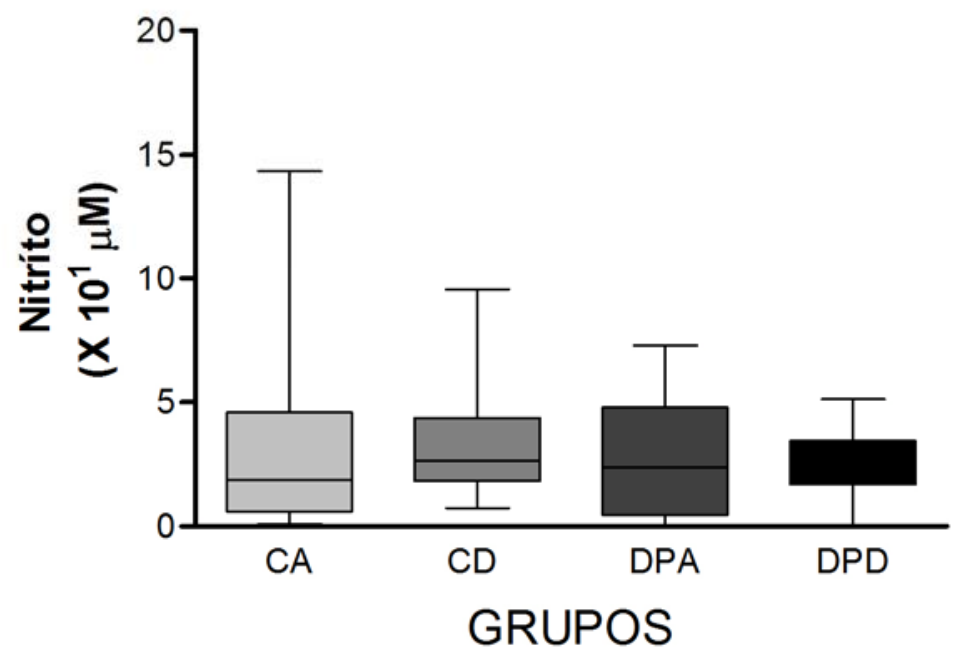

Figura 8- Gráfico que representa as concentrações salivares submandibulares e sublinguais de nitrito (mediana e percentis) de pacientes antes e depois do tratamento periodontal básico, assim como os controles antes e após o tratamento. Não há diferenças estatisticamente significantes entre os grupos CA versus CD, DPA versus DPD, CA versus DPA. CA: pacientes controle no inicio do estudo; CD: pacientes controle 3 meses após o estudo; PDA: pacientes com doença periodontal no inicio do estudo; PDP: pacientes com doença periodontal tratada após 3 meses de estudo. 


\subsection{Concentrações de nitrito no sangue e plasma}

\subsubsection{Concentrações de nitrito no sangue total}

A Figura 9 nos mostra as concentrações de nitrito no sangue total. Os grupos $\mathrm{CA}$, mediana $=1,41(\mathrm{Q} 1=1,1 / \mathrm{Q} 3=2,21)$ versus $C D$, mediana $=0,99(\mathrm{Q} 1=0,58 / \mathrm{Q} 3=$ 2,11) não apresentaram diferenças estatisticamente significantes entre suas medianas, $p=0,64$. Os grupos CA, mediana=1,41 $(\mathrm{Q} 1=1,1 / \mathrm{Q} 3=2,21)$ versus DPA, mediana= 1,61 $(\mathrm{Q} 1=1,12 / \mathrm{Q} 3=2,3)$ também não apresentam diferenças estatísticas, $p=0,59$. Já os grupos DPA, mediana= $1,61(\mathrm{Q} 1=1,12 / \mathrm{Q} 3=2,3)$ versus $\mathrm{DPD}$, mediana $=1,45(\mathrm{Q} 1=0,61 / \mathrm{Q} 3=1,87)$ apresentam diferenças estatisticamente significantes, $p=0,026$. Os grupos CA e DPA não apresentaram distribuição normal, os grupos CD e DPD apresentaram distribuição normal, por essa feita foram empregados os testes Wilcoxon teste, Mann-Whitney teste.

\section{Sangue Total}

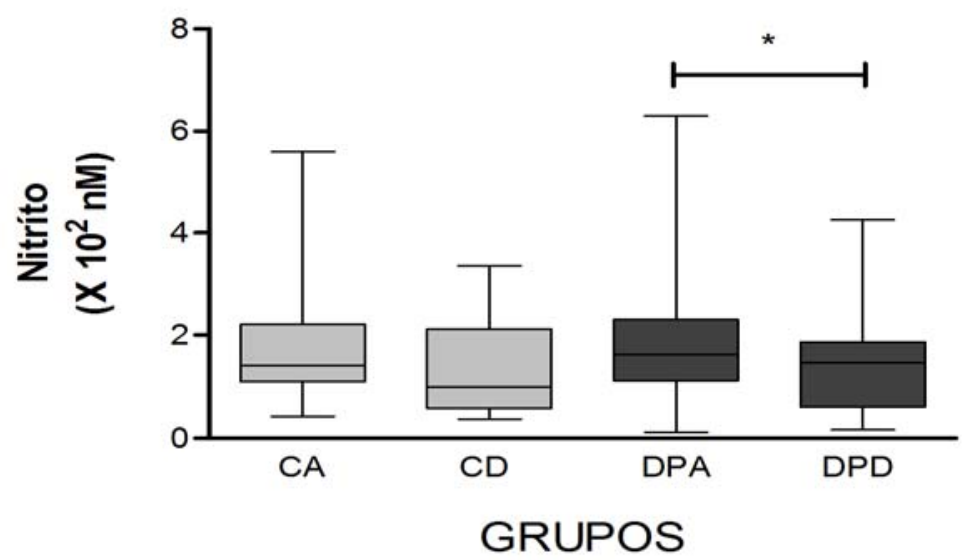

Figura 9- Concentrações de nitrito no sangue total (mediana e percentis). Observamos que não houve diferença estatisticamente significantes entre os grupos CA versus CD, bem como CA versus DPA. Houve diferença estatisticamente significante entre CA versus DPA. CA : pacientes controle no inicio do estudo; CD: pacientes controle 3 meses após o estudo; PDA: pacientes com doença periodontal no inicio do estudo; PDP: pacientes com doença periodontal tratada após 3 meses de estudo, * $p<0,05$. 


\subsubsection{Concentrações de nitrito no plasma}

A Figura 10 nos indica que não houve diferenças estatisticamente significantes entre as medianas dos grupos CA, mediana=0,51 $(Q 1=0,36 / Q 3=$ $1,09)$ versus $C D$, mediana $=0,63(Q 1=0,56 / Q 3=0,82)$, bem como nos grupos DPA, mediana $=0,60(\mathrm{Q} 1=0,37 / \mathrm{Q} 3=0,97)$ versus $\mathrm{DPD}$, mediana=0,5 $(\mathrm{Q} 1=0,39 / \mathrm{Q} 3=$ 0,83) e CA, mediana=0,51 $(\mathrm{Q} 1=0,36 / \mathrm{Q} 3=1,09)$ versus $\mathrm{DPA}$, mediana=0,6 $(\mathrm{Q} 1=$ $0,37 / \mathrm{Q} 3=0,97)$. Com $p=0,42 ; p=0,39 ; p=0,87$, respectivamente. Os grupos CA e DPD não apresentaram distribuição normal, já os grupos CD e DPA apresentaram distribuição norma. Assim, os testes empregados foram Wilconxon teste e MannWhitney.

\section{Plasma}

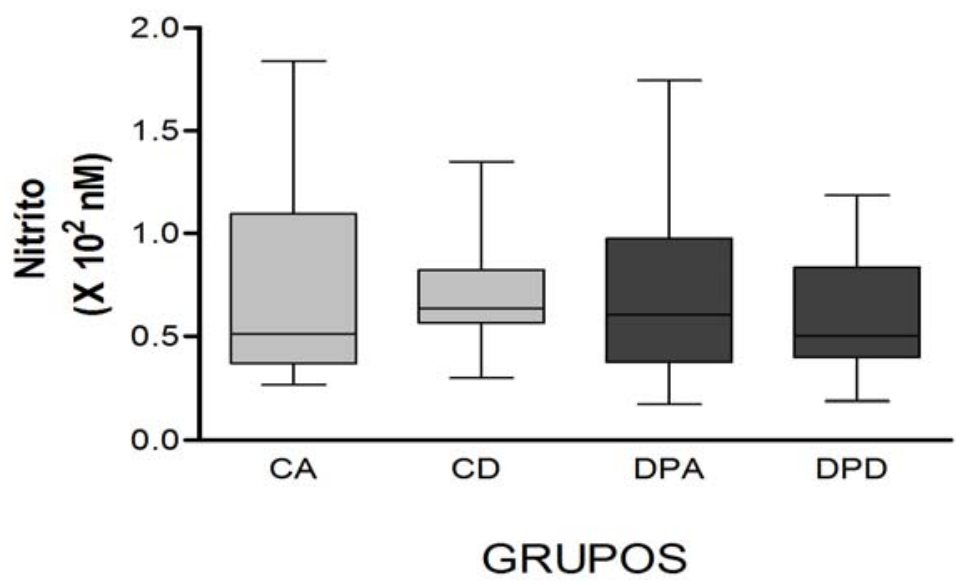

Figura 10- Gráfico que representa as concentrações de nitrito plasmático (mediana e percentis) de pacientes antes e depois do tratamento periodontal básico, assim como os controles, antes e depois do tratamento. Não há diferenças estatisticamente significantes entre os grupos CA versus CD, DPA versus DPD, CA versus DPA. CA: pacientes controle no inicio do estudo; CD: pacientes controle 3 meses após o estudo; PDA: pacientes com doença periodontal no inicio do estudo; PDP: pacientes com doença periodontal tratada após 3 meses de estudo. 


\subsubsection{Concentrações de nitrito em eritrócitos}

A Figura 11 nos mostra as concentrações de nitrito nos eritrócitos. Os grupos CA $(0,45 \pm 0,41)$ versus CD $(0,46 \pm 0,47)$ não apresentaram médias com diferenças estatisticamente significantes, $p=0,30$. Os grupos CA $(0,45 \pm 0,41)$ versus DPA $(3,5$ $\pm 13,33$ ) também não apresentam diferenças estatísticas, $p=0,49$. Já os grupos DPA $(0,57 \pm 0,44)$ versus DPD $(0,29 \pm 0,22)$ apresentam diferenças estatisticamente significantes, $p=0,02$. Todos os grupos apresentaram distribuição normal, dessa forma o teste t pareado e teste t não pareado foi empregado.

\section{Eritrócitos}

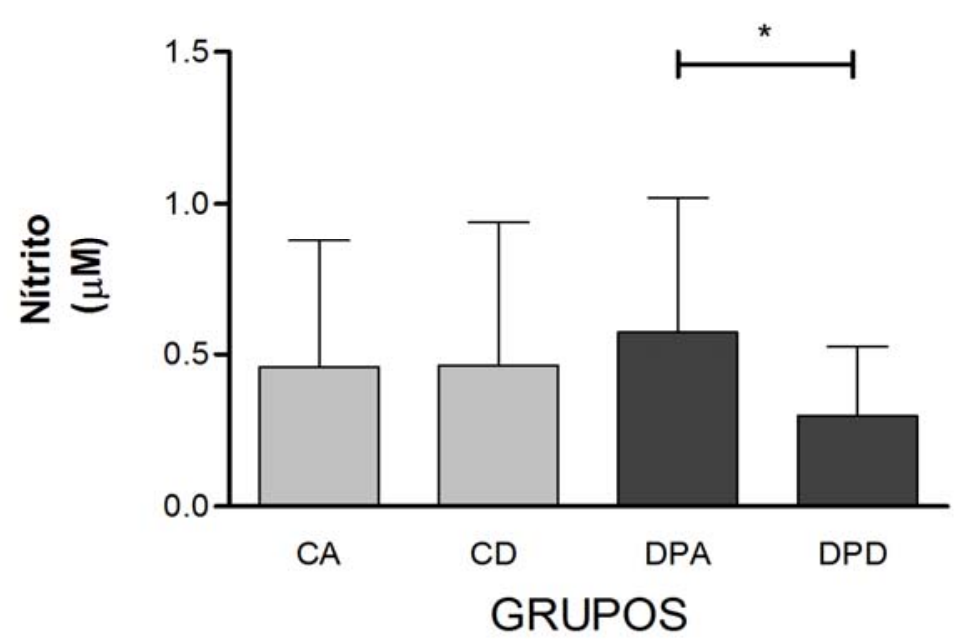

Figura 11- Concentrações de nitrito nos eritrócitos (média \pm desvio padrão). Observamos que não houve diferença estatisticamente significantes entre os grupos $C A$ versus $C D$, bem como $C A$ versus DPA. Houve diferença estatisticamente significante entre CA versus DPA. CA: pacientes controle no inicio do estudo; CD: pacientes controle 3 meses após o estudo; PDA: pacientes com doença periodontal no inicio do estudo; PDP: pacientes com doença periodontal tratada após 3 meses de estudo, ${ }^{*} p<0,05$. 
DISCUSSÃO 


\section{DISCUSSÂO}

\subsection{Considerações gerais}

Este é um estudo comparativo, o qual teve como objetivo relacionar as concentrações de óxido nítrico (NO), através do nitrito do sangue e saliva em pacientes com doença periodontal.

Até o presente momento este estudo se mostra inédito, uma vez que a metodologia empregada nele, através da análise de NO por quimiluminescência não foi realizada na comparação entre saliva e sangue. Aliado a esse fato também se mostra inédito por comparar grupos de pacientes doentes e tratados com tratamento periodontal não cirúrgico e controles saudáveis em dois momentos distintos, antes do tratamento e após 3 meses.

Tanto as propriedades antibacterianas quanto aquelas desencadeadoras de progressão da doença periodontal do NO são fundamentais para a evolução da doença. Desta feita, a contribuição do NO tanto nos tecidos periodontais quanto nos fluidos bucais, como a saliva e o fluido crevicular gengival foi relatada em diversos estudos experimentais.

Tem sido sugerido que o desequilíbrio nas concentrações de NO seja um fator limítrofe entre a saúde e a doença periodontal, ou seja, a atividade de nitrato redutase geraria NO suficiente para inibir o crescimento de várias bactérias, entretanto, em adicional a sua propriedade antimicrobiana o NO poderia também atuar na promoção da inflamação periodontal e reabsorção óssea (MATEJKA et al., 1998). Tem sido descrito que as concentraçõs de $200 \mu \mathrm{M}$ a $500 \mu \mathrm{M}$ de nitrito apresenta propriedades antibacterianas (ALLAKER et al., 2000). No entanto altas 
quantidades de NO, desencadeadas pela ação inflamatória, podem causar o dano tecidual, via atividade proteolítica excessiva, o que resulta na perda do tecido de sustentação do dente, cemento, ligamento periodontal e osso alveolar.

\subsection{Interpretação dos dados clínicos}

Neste estudo, partimos do pressuposto que o tratamento periodontal básico é a alternativa mais viável para o mesmo, atualmente.

Notamos nos nossos resultados que houve uma diminuição significativa no sangramento a sondagem, após a raspagem radicular, o que está em acordo com a literatura (LANG et al., 1990a; LANG et al., 1990b; CLAFFEY \& EGELBERG, 1995), uma vez que após a raspagem a inflamação diminui, bem como os seus sinais clássicos, como calor, tumor e rubor.

Também observamos, como esperado, uma diminuição nas níveis de sangramento a sondagem nos pacientes controle $(C A$, média= $16,12 \%$; $C D$, média= 10,59 \%; p<0,0005), o que indica a presença de gengivite nestes. Esta diminuição do sangramento pode ser explicada pela melhoria de higiene bucal proporcionada com as seções de profilaxia, escovação supervisionada e orientações (LÖE et al., 1965).

Quando comparamos os grupos doentes antes do tratamento com o grupo controle antes do tratamento (CA, média= $16,12 \%$ e DPA, média $=43,7 \%$; $p<0,0001)$, notamos que existe uma grande diferença entre o sangramento a sondagem de ambos, fato que reflete os níveis de saúde e doença periodontal.

O nível clinico de inserção é a distância entre a junção cemento esmalte e a margem gengival e reflete o estado de progressão da doença, assim como outros parâmetros já citados. 
O nível clinico de inserção antes do tratamento se demonstrou elevado quando comparado com o mesmo parâmetro depois do tratamento, nos pacientes doentes (DPA, média= 2,86 mm e DPD, média=2,46 mm $p<0,0001$ ). Este fato pode ser explicado através da melhora nos sítios inflamatórios, após o tratamento básico periodontal não cirurgico. Da mesma forma que a escovação supervisionada e as seções de profilaxia melhoraram nos pacientes saudáveis, este mesmo parâmetro.

Quando comparamos os grupos doentes com os saudáveis notamos que há diferença estatisticamente significante $(C A$, média= 2,09 mm DPA, média= 2,86 mm p<0,0002).O grupo doente apresenta indivíduos com maior perda de inserção em relação aos saudáveis, fato que reflete a progressão da doença.

A profundidade de sondagem, da mesma forma apresenta diferenças estatisticamente significantes antes e após o tratamento periodontal não cirúrgico (DPA, média= 2,31 mm DPD, média= 1,92 mm p<0,0001), o que indica que pode ter ocorrido melhora nas condições inflamatórias da bolsa periodontal e um possível restabelecimento da saúde através de uma pseudo ligação entre o epitélio da bolsa e o cemento radicular.

Quando comparamos o grupo controle antes e após o tratamento (CA, média $=1,51 \mathrm{~mm} \mathrm{CD}$, média=1,49 $\mathrm{mm} p=0,31$ ), podemos inferir que não há diferenças estatisticamente significantes, uma vez que neste grupo não há bolsa periodontal e o nível de profundidade se estabelece o mesmo no decorrer dos 3 meses de avaliação deste estudo.

Nos sítios com profundidade de sondagem maiores que $4 \mathrm{~mm}$, como notamos pela Figura 5, podemos inferir que doentes periodontalmente comprometidos apresentam bolsas periodontais profundas, as quais após o tratamento periodontal básico parecem restabelecer as condições saudáveis e esse parâmetro se mostra 
diminuído (DPA, média= 9,79; DPD, média=5,02; $p<0,0001$ ). No grupo pacientes saudáveis, quase não existe profundidade de sondagem desta monta (CA, média=0,02; CD, média=0,0). Dessa forma, podemos concluir que existem diferenças estatisticamente relevantes entre o grupo doente e o grupo saudável (CA, média=0,02; DPA, média=9,79; $p<0,0001)$.

Tais achados clínicos demonstram ter sido realizado um tratamento periodontal eficaz neste estudo. Fato que propicia um estudo fidedigno em relação à comparação das concentrações de NO, sanguíneos e salivares, antes e após o tratamento periodontal básico.

\section{3 Óxido Nítrico na Saliva}

Alguns trabalhos citados nesta dissertação relatam aumentos de NO salivar e de NO nos tecidos periodontais, através da utilização da reação de Griess como método de análise (LOHINAI et al., 1998; MATEJKA et al., 1998; GULLU et al., 2005; REHER et al., 2007; PARWANI et al., 2012). Este método avalia a quantidade de NO de forma indireta pela mensuração de nitrito e nitrato, sem distinção, $N O_{x}$ (nitrato e nitrito).

No entanto, nosso estudo, utilizou o ensaio por quimiluminescência para a aferição dos níveis de NO a partir das quantidades de nitrito. Tal metodologia se mostra inovadora e nossos dados apresentam resultados ainda não descritos na literatura.

Assim como Aurer et al. (2010) relatou que as diferenças encontradas entre os grupos, neste estudo, não podem ser atribuídas à quantidade de nitrato ingerido na dieta, uma vez que mesmo ingerido grandes quantidades, não proporciona viés 
na quantificação do NO. Prudentemente, foi tomado o devido cuidado com a metodologia, nesta dissertação.

Com relação aos gráficos de saliva, as concentrações de nitrito na saliva total, saliva submandibular/sublingual e saliva parotídea apresentam-se de forma decrescente, sendo os valores médios encontrados em nosso estudo variando, respectivamente: de 55 à $92 \mu \mathrm{M} ; 24,8$ à $34,2 \mu \mathrm{M}$ e 0,58 à $0,85 \mu \mathrm{M}$, respectivamente. Isso está de acordo com a literatura, visto que Aurer et al. (2010) mostraram valores da mesma ordem de magnitude e também valores decrescentes da saliva total para a saliva parotídea. Aurer et al. (2010) descrevem que a quantidade de nitrito na saliva total é $22,4 \mu \mathrm{mol} / \mathrm{L}$ (média em pacientes saudáveis), $21,2 \mu \mathrm{mol} / \mathrm{L}$ (média em pacientes saudáveis) na saliva sumandibular/sublingual e esta é maior do que a concentração verificada na saliva da parótida $(10,2 \mu \mathrm{mol} / \mathrm{L}$ - média em pacientes saudáveis).

Notamos pela Figura 6 que há maiores concentrações de NO no grupo controle (CA, CD) do que no grupo doentes (DPA, DPD). Devido à alta sensibilidade da análise por quimiluminescência, nossos valores $(C A=69 \mu \mathrm{M} ; C D=55 \mu \mathrm{M})$ nos grupos controle se aproximam dos valores encontrados na literatura, os quais apresentam propriedades antibacterianas $(0,2$ a $0,5 \mathrm{mM})$. A presença de NO nos grupos controle, em concentrações da mesma ordem de magnitude daquelas com descrito efeito antimicrobiano contra patógenos periodontais, sugere que o NO nos grupos controle possa contribuir para a saúde periodontal destes, uma vez que o NO atua como agente antimicrobiano, inibindo assim a progressão da DP (ALLAKER et al., 2001).

As concentrações de NO encontradas podem ser um pouco diferentes (embora na mesma ordem de magnitude), pelo fato de termos utilizado outro método 
de medidas de NO (análise por quimiluminescência em detrimento a análise por reação de Griess).

Na saliva total encontramos concentrações de NO diminuídas no grupo DPA em comparação com CA (respectivamente $44 \mu \mathrm{M}, 6,9 \mu \mathrm{M}, p=0,04$ ). Esta diferença estatisticamente significante pode ser explicada pelo fato de haver menor quantidade de NO nos doentes, uma vez que não temos neste grupo a atuação das propriedades antibacterianas do NO salivar, conseqüentemente, maior proliferação bacteriana e progressão da DP.

Alternativamente, podemos supor que exista a influência da arginase, uma enzima que compete na produção de NO, a qual se mostra diminuída na saúde periodontal e aumentada na doença. A arginase foi mais alta nos pacientes do grupo doente $(2,8 \mathrm{IU} / \mathrm{ml})$ do que nos controles (1,4IU/ml), $p<0,01$ (OZMERIÇ et al., 2000).

Segundo Schneider \& Dy (1985) a arginase seria originada nos macrófagos. Certas bactérias patogênicas da doença periodontal poderiam assim criar um processo inflamatório que proporcionaria a formação de arginase.

Assim, uma possível explicação para a diminuição nas concentrações de nitrito nos grupos doentes em relação aos controles é a diminuição da atividade de arginase nos controles (CA; CD), ocorrendo, portanto, maior concentração de NO, que por sua vez atua como antibacteriano. Nos grupos DP (DPA; DPD) poderíamos supor haver maior quantidade de arginase inibindo a produção de NO e conseqüentemente aumentando a progressão da doença. No entanto, mais estudos precisariam medir a atividade de arginase, para confirmar essa possibilidade.

Não foi visto aumento das concentrações de NO na saliva dos pacientes após o tratamento periodontal, o que pode ser devido ao fato da atividade de arginase continuar alta neste grupo de doentes mesmo após o tratamento. 


\section{4 Óxido Nítrico no Sangue}

Os valores de nitrito obtidos no sangue total, plasma e eritrócitos mostram diminuição dos valores da mediana de NO no grupo DPD em comparação com DPA, tanto no sangue total (DPA=161 nM; DPD=145 nM; $p=0,026)$ quanto nos eritrócitos $(\mathrm{DPA}=0,57 \mu \mathrm{M} ; \quad \mathrm{DPD}=0,29 \mu \mathrm{M} ; \quad p=0,02)$ houve diferenças estatisticamente significantes.

À primeira vista se poderia pensar que a explicação estivesse relacionada com a diminuição da carga bacteriana, uma vez que está bem aceito no meio que as bactérias comensais da boca seriam as responsáveis pelo conversão do nitrato da saliva em nitrito (TANNENBAUM et al., 1976), o qual é deglutido e convertido a NO no meio ácido do estômago. Experimentos com omeprazol, um inibidor da bomba de prótons do estômago, mostraram que existe menos NO no sangue após o uso desta droga (LUNDBERG et al., 1994). Assim, a diminuição das bactérias poderia se refletir na diminuição do NO no sangue, medido neste estudo como nitrito. Entretanto, como foi medido NO na saliva, também se esperaria detectar menos nitrito na saliva com a diminuição da carga bacteriana. Por esta razão, esta explicação não faz sentido para entender ou justificar a diminuição de nitrito no sangue verificada em nosso estudo. Portanto, sugerimos que haja uma dissociação entre as concentrações de nitrito na saliva e no sangue. Assim, a pergunta seguinte seria: quais são os resultados de nitrito no sangue e como explicar os resultados vistos no sangue?

Os resultados de nitrito no sangue total e nos eritrócitos mostram valores de nitrito no grupo $\mathrm{CA}$ (sangue total= $141 \mathrm{nM} /$ eritrócitos $=0,45 \mu \mathrm{M}$ ), no grupo $\mathrm{CD}$ (sangue total $=99 \mathrm{nM} /$ eritrócitos $=0,46 \mu \mathrm{M}$ ), no grupo DPA (sangue total= $161 \mathrm{nM} /$ 
eritrócitos $=0,57 \mu \mathrm{M}$ ) e no grupo DPD (sangue total= $145 \mathrm{nM} /$ eritrócitos= $0,29 \mu \mathrm{M}$ ), havendo diminuição estatisticamente significante nos valores de nitrito no grupo DPD em relação à DPA, $p=0,026$ (sangue total) e $p=0,024$ (eritrócitos).

Anteriormente, já descrevemos que este grupo de pacientes mostrou esta mesma diminuição no grupo DPD em relação ao grupo DPA nas concentrações de proteína C reativa, IL-6 (MARCACCINI et al., 2009a), MMP-8 e MMP-9 (MARCACCINI et al., 2009b). O aumento destas moléculas em relação ao grupo controle e a diminuição depois do tratamento sugere que a carga inflamatória diminua após o tratamento periodontal, o que está de acordo com vários trabalhos que mostram a importância do tratamento periodontal para diminuir marcadores inflamatórios no plasma (D'AIUTO et al., 2005; O’CONNEL et al., 2008; VIDAL et al.,2009).

As variações no nitrito vistas no grupo DPD das amostra de eritrócitos e sangue total sugerem que também o nitrito poderia sofrer influência do estado inflamatório dos pacientes, que foi modificado pelo tratamento. Neste caso, poderiase formular a hipótese de que o nitrito detectado no sangue total e eritrócitos refletisse a atividade de iNOS, molécula envolvida em processos inflamatórios (FOSTERMMAN et al., 1994).

Até o momento, não se sabe qual a porcentagem de nitrito de sangue total seria derivada da eNOS ou da iNOS. Este aspecto precisa ser estudado mais a fundo, pois mesmo gerando NO, uma molécula com aspectos benéficos a saúde, a atividade aumentada da iNOS certamente traz conseqüências indesejáveis para o organismo.

Ao que sabemos, não há até o momento trabalhos com doença periodontal sobre a atividade e quantidade de iNOS em leucócitos ou em outro tecido, e como esta atividade ou quantidade se reflete nos níveis de NO no sangue total. 
CONCLUSÕES 


\section{CONCLUSÕES}

1. As concentrações de nitrito foram da ordem de micromolar na saliva e de nanomolar no sangue total, guardando uma relação de cerca de 1000 vezes entre estes 2 fluidos.

2. As concentrações de nitrito obtidas foram decrescentes na seguinte ordem: saliva total, saliva sumandibular/sublingual, saliva parotídea, eritrócitos,sangue total e plasma.

3. Na saliva, os pacientes do grupo DPA e DPD apresentaram concentrações menores de nitrito em relação ao CA e CD $(p<0.05)$, e o tratamento periodontal não teve efeito sobre as concentrações de nitrito.

4. Houve diminuição estatisticamente significante nas concentrações de nitrito no sangue total e eritrócitos após o tratamento periodontal.

5. Os resultados sugerem que não há relação entre as concentrações salivares e sanguíneas de nitrito.

6. Os resultados de nitrito no sangue total sugerem que a diminuição após o tratamento possa ser resultado da diminuição na atividade inflamatória nos pacientes com DP. 
REFERÊNCIAS 


\section{REFERÊNCIAS}

Allaker, R. P.; Silva Mendez, L. S.; Hardie, J. M; Benjamin, J. Antimicrobial effect of acidified nitrite on periodontal bacteria, Oral Microbilogy and Immunology, 16, 253-256, 2001.

Almstahl, A.; Wikstrom, M.; Groenink, J. Lactoferrin, amylase and mucin MUC5B an their relation to the oral microflora in hyposalivation of diferrent origins. Oral Microbioly and Immunology, 16, 345-52, 2001.

Amerongen, A. V.; Veerman, E. C. Saliva the defender of oral cavity. Oral Disease, 8,12-22, 2002.

Armitage G. C. Development of classification system for periodontal disease an conditions. Annals of Periodontoloy, 4(1), 1-6, 1999.

Aurer, A.; Aleksic, J.; Ivic-Kardum, M.; Aurer, J.; Cuolo, F. Nitric oxide synthesis is decrease in periodontits. Journal of Clinical Periodontology, 28, 565-8, 2010.

Bahar, G.; Feinmesser, R. Salivary analysis in oral cancer patients: DNA and protein oxidation, reactive nitrogen species, and antioxidant profile. Cancer, 109-1, 53-59, 2006.

Batista, A. C; Silva, T. A.; Chun, J. H.; Lara, V. S. Nitric oxide synthesis and severity of human periodontal disease. Oral Disease, 8, 254-260, 2002.

Beck J.; Garcia R.; Heiss G.; Vokonas P. S.; Offenbacher S. Periodontal disease and cardiovascular disease. Journal of Periodontology, 67, 1123-37, 1996.

Beck J.; Slade, G.; Offenbacher S. Oral disease, cardiovascular disease an systemic inflammation. Periodontology, 23, 110-20, 2000.

Birkedal- Hansen, H.; Moore, W. G.; Bodden, M. K.; Windsor, L. J.; Birkedal- Hansen, B.; DeCarlo, A.; Engler, J. A. Matrix metalloproteinases: a review.Critical reviews in Oral Biology and Medicine, 4(2), 197-250, 1993.

Bizarro, S.; van der Velden, U.; ten Heggeler, J.M. Periodontits is characterizeted by elevated PAI-1 activity. Journal of Clinical Periodontology, 34, 574-580, 2007. 
Brasil. Ministério da Saúde. Secretaria de Atenção à Saúde. Departamento de Atenção Básica. Projeto SB Brasil 2003: condições de saúde bucal da população brasileira 2002- 2003: resultados principais. Brasília: Ministério da Saúde; 2004.

Brennan, P.A.; Thomas, G.J.; Langdon, J.D. The role of nitric oxide in oral diseases. Archives of Oral Biololy, 48,93-100, 2003.

Brew, K.; Dinakarpandian, D.; Nagase, H. Tissue inhibitor of metalloproteinases: evolution, structure and function. Biochimica et Biophysic Acta, 1477(1-2), 267-283, 2000.

Bryan, N. S.; Grisham, M. B. Methods to detect Nitric Oxide and its Metabolites in Biological samples. Free Radical Biology and Medicine, 43(5), 645-657, 2007.

Calver, A.; Collier, J.; Vallance, P. Nitric oxide and cardiovascular control. Experimental Physiology 78, 303-326, 1993

Carossa, S.; Pera, P.; Doglio, P.; Lombardo, S.; Colagrande, P.; Brussino, L.; Rolla, G.; Bucca, C. Oral nitric oxide during plaque deposition. European Journal of Clinical Investigation, 31, 876-9, 2001.

Carranza F. A.; Newman M. G. Periodontia Clínica. 9a Edição. Rio de Janeiro. Guanabara Koogan. 2002.

Claffey, N.; Egelberg, J. Clinical indicators of probing attachment loss following initial periodontal treatment in advanced periodontits patients. Journal of Clinical Periodontology, 22, 690-696, 1995.

Corwin, H. L.; Getinger, A.; Pearl, R.G. The CRIT study: anemia and blood transfusion in the critically illcurrent pratice in USA. Critical Care Medicine, 32, 39-52, 2004.

Coussens, L. M.; Werb, Z. Matrix metalloproteinases and the development of cancer. Chemestry \& Biology, 3(11),895-904, 1996.

D’Aiuto, F.; Nibali L.; Mohamed-Ali V.; Vallance P.; Tonetti M. S. Periodontal therapy: a novel non-drug-induced experimental model to study human inflammation. Journal of Periodontal Research, 39, 294-99, 2004. 
D’Aiuto, F.; Nibali, L.; Parkar, M.; Survan, J.; Tonetti, M. S. Short-term effects of intensive periodontal therapy on serum inflammatory markers and cholesterol. Journal of Dental Research, 84,269-273,2005.

Daghigh F.; Borghaei R. C., "Human gingival fibroblasts produce nitric oxide in response to proinflammatory cytokines". Journal of Periodontology 2002 ;73$4, .392-400$.

De Lorenzo J. L., Biofilme dental, Microbiologia para estudante de Odontologia. São Paulo, Atheneu, 2006, 73-85.

Dean, D. D.; Martel- Pelletier, J.; Pelletier, J. P.; Howell, D. S.; Woessner, J. F. Jr; Evidence for metalloproteinase and metalloproteinase inhibitor imbalance in human osteoarthritic cartilage. Jounal of Clinical Investigation, 84(2), 678-85, 1989.

Dixon, D. R.; Bainbridge, B. W.; Darveau, R. P. Modulation of the innate immune response within the periodontium. Periodontology 2000, 35,53-74, 2004.

Farnaud, S. J.; Kosti, O. Saliva: physiology and diagnostic potential in health and disease. Scientific World Journal ,10, 434-456, 2010.

Farnaud, S. J.; Kosti, O. Saliva: physiology and diagnostic potential in health and disease. Scientific World Journal, 10, 434-456, 2010.

Forner, L.; Larsen, T.; Kilian, M.; Holmstrup, P. Incidence of bacteremia after chew, tooth brushing and scaling in individuals with periodontal inflammation. Journal of Clinical Periodontology, 33, 401-407, 2006.

Fostermman, U.; Closs, E.I.; Pollock, J.S.; Nakame, M.; Schwarz, P.; Gath, I.; Kleinert, $H$. Nitric oxide synthase isozymes. Characterization, purification, molecular cloning, and functions.

Gasson, J. C.; Golde, D. W. Kaufman, S. E.; Westbrook, C. A.; Hewick, R. M.; Kaufman, R. J; Wong, G. G.; Temple, P. A.; Leary, A. C.; Brown, E. L. Molecular characterization and expression of the gene encoding human erythoid-potentiating activity. Nature, 315(6022), 768-771,1985.

Gemmell, E.; Marshall, R. I.; Seymour, G. J. Cytokines and prostaglandins in immune homeostasis and tissue destruction in periodontal disease. Periodontology 2000,14,112-143, 1997. 
Gomez, D. E.; Alonso, D. F.; Yoshiji, H.; Thorgeisson, U. P. Tissue inhibitor metalloproteinases: structure, regulation and biological functions. European Journal of Cell Biology, 74(2), 111-122, 1997.

Gorska, R.; Gregorek, H.; Kowalski, J.; Laskus-Perendyk, A.; Syczewska, M.; Madalisnki, K. Relationship between clinical parameters and cytokines profile in inflamed gingival tissue and serum samples from patients with chronic periodontits. Journal of Clinical Periodontology, 30, 1046-1052, 2003.

Greabu, M.; Battino, M. Saliva- a diagnostic window to the body, both in health and in disease. Journal of Medicine and Life, 2(2), 124-132, 2009.

Grisham, M. B; Jhonson, G. G; Gautreax, M. D.; Berg, R. D. Measurement of Nitrate and nitrite in extracellular fluid: a window to systemic nitric oxide metabolism. Methods, 7, 84-90,1995.

Gross, J.; Lapiere, C. M. Collagenolytic activity in amphibian tissues: a tissue culture assay. Proceedings of the National Academy of Science of the United State of America, 48, 1014-1022, 1962.

Guedes, L.; Mansoor, A.; Birkedal- Hansen, B.; Lim, M. S.; Fukushima, P.; Venzon, D.; Stetler-Stevenson, W. G.; Stetler-Stevenson, M. Tissue inhibitor of metalloproteinases 1 regulation of interleukin-10 in B-cell differentiation and lymphomagenesis. Blood, 97(6): 1796-802, 2001.

Gullu, C.; Ozmeric, N.; Tokman, B; Elgun, S.; Balos, K. Effectiveness of scarling root planning versus modified Widman flap on nitric oxide synthase and arginase activity in patients with chronic periodontitis. Journal of Periodontal Research, 40, 168-175, 2005.

Guyton, A. C.; Hall, J. E. Tratado de Fisiologia Médica. Rio de Janeiro. Saunders Elsevier. 2006. 792-94.

Guyton, A. C.; Hall, J. E. Tratado de Fisiologia Médica. Rio de Janeiro. Saunders Elsevier. 2006. 199-200.

Haeckel, R.; Hanecke, P. Application of saliva for drug monitoring. An in vivo model for transmembrane transport. European Jouenal of Clinical Chemistry and Clinical Biochemistry, 34(3), 171-191, 1996.

Hansan, N.; McColgan, P.; Bentley, P.; Edwards, R.; Sharma, P. Towards the identification of blood biomarkers for acute stroke in humans: a comprehensive systematic review. British Journal of Clinical Pharmacology. 74, 249, 2010. 
Heasman, L.; Stacey, F.; Preshaw, P. M.; McCracken, G. I.; Hepburn, S.; Heasman, $P$. A. The effect of smoking on periodontal treatment response: a review of clinical evidence, Journal of Clinical Periodontology, 33, 241-53, 2006.

Heitz-Mayfield, L. J. A. Disease progression: identification of high-risk groups and individuals for preiodontitis. Journal of Clinical Periodontology, 32, 196-209, 2005.

Ide, M.; Jadev, D.; Coward, P. Y.; Crook, M.; Barclay, G. R.; Wilson, R. F. The short term effects of treatment of chronic periodontits on circulation levels of endotoxin , C-reative protein, tumor necrosis factor alpha, and interleukin-6. Jounal of Periodontology, 75, 420-428, 2004.

Jenkins, D. C.; Charles, I. G. Roles of nitric oxide in tumor growth, Medical Sciences, 92 (10), 4392-4396, 1995.

Jin Y.; Hak-Kong, Y. Supragengival; calculus: formation and control. Critical Reviews in Oral Biology and Medice, 13, 426-41, 2002.

Johnson, G. K.; Slach, N. A. Impact of tabacco use on periodontal status. Journal of Dental Education, 65, 313-321, 2001.

Junqueira, L. C.; Carneiro, J. Histologia Básica. Rio de Janeiro, Guanabara \& Koogan, 2004,223-237.

Kawamata, H.; Kameyama, S.; Kawai, K.; Tanaka, Y.; Nan, L.; Barch, D.H.; StleterStevenson, W.G.; Oyasu, R. Marked acceleration of the metastatic phenotype of a rat bladder carcinoma cell line by the expression of human gelatinase $A$. Internation Journal of Cancer, 63(4), 568-75, 1995.

Kelly, T.; Yan, Y.; Osborne, R.; Athota, A.; Rozypal, T.; Colclasure, J.C.; Chu, W. Proteolysis of extracelullar matrix by invadopodia facilitates human breast cancer cell invasion and is mediated by matrix metalloproteinases.Clinical \& Experimental Metastasis, 16(6), 501-512, 1998.

Kendall, H. K.; Haase, H. R.; Li, H.; Xiao, Y.; Bartold, P. M. Nitric oxide synthase type-II is syhthesized by human gingival tissue and cultured human gingival fibroblasts. Journal of Periodontal Research,35,194- 200, 2000.

Kinane, D. F.; Berglundh, T.; Lindhe, J. Pathogenesis of Periodontitis. Clinical Periodontology and Implant Dentristy. $5^{\text {th }}$ Edition. Oxford: Blackwell Publishing, 2008. 285-99. 
Kornman, K.; Page, R. C.; Tonetti, M. S. The host response to the microbial challenge in periodontitis: assembling the players. Periodontology 2000, 14 , 33-53, 1997.

Kramer, A. H.; Zygun, D. A. Anemia and redblood cell transfusion in neucritical care. Critical Care, 13(3), R89, 2009.

Krawiec, T.; Vorp, D. A. Adult stem cell-based tissue engineered blood vessels: A review. Biomaterials, 33, 3388-3400, 2012.

Kroncke, K.; Fehsel, K.; Kolb-Bachofen, V. Nitric oxide: citotoxity versus cytoprotection- how, why, when, and where? Jounal of Biological Chemistry, 1, 107-120, 1997.

Kweider, M.; Lowe, G. D.; Murray, G. D.; Kinane, D. F.; McGowan, D.A. Dental disease, fibrinogen and white cell count: links with myocardial infarction? Scottish Medical Journal, 38, 73-78, 1993.

Lang N.P; Orsanic, T.; Gusbert, F. A.; Siegrist, B.E. Bleeding on probing- A predictor for progression for periodontal disease? Journal of Clinical Periodontology, 13, 590-596, 1990b.

Lang, N. P.; Adler, R.; Joss, A.; Nyman, S. Absence of bleeding on probing. An indicator of periodontal stability. Journal of Clinical Periodontology, 17, 714-21, 1990a.

Lärfars, G.; Lantoine, F. Electrochemical detection of nitric oxide production in human polymorphonuclear neutrophil leukocytes. Scandinavian Journal of Clinical and Laboratory Investigation, 59 (5) 361-368, 1998.

Laurent, M.; Leproivre, M.; Tenu, J. Kinetic modeling of nitric oxide gradient generated in vitro by adherent cells expressing inducible nitric oxide synthase. Biochemistry Journal, 314, 109-113, 1996.

Lawrence, H. P. Salivary markers of systemic disease: noninvasive diagnosis of disease and monitoring of general health. Journal of Canadian Dental Association, 68(3), 170-174,2002.

Liew, F. Y. Nitric oxide in infectious and autoimmune diseases. Ciba Foundation Symposium 195, 234-239, 239-244, 1995b. 
Liew, F. Y. Regulation of lymphocyte functions by nitric oxide. Current Opinion in Immunology 7, 396-399, 1995a.

Linden, G. J.; Mullally, B. H.; Freeman, R. Stress and the progression of periodontal disease. Journal of Clinical Periodontology, 23, 675-680, 1996.

Löe, H.; Theilade, E.; Jensen, S.B. Experimental gengivits in man. Journal of Periodontology, 36, 177- 87, 1965.

Lohinai, Z.; Benedek, P.; Fehér, E.; Gyorfi, A.; Rosivall, L.; Fazekas, A.; Salzman, A.L.; Szabó, C. Protective effects of mercaptoethylguanidine, a selective inhibitor of inducible nitric oxide synthase, in ligadure-induced periodontits in the rat. British Journal of Pharmacology, 123, 353-360, 1998.

Looms, D.; Tritsaris, K.; Pedersen, A. M.; Nauntofte, B.; Dissing, S. Nitric oxide signalling in salivary glands. Journal of Oral Pathology \& Medicine. 31, 569-84, 2001.

Loos, B. G.; Craandijk, J.; Hoek, F. J.; Wertheim-van Dillen,P. M. E.; van der Velden, U. Elevation of systemic markers related to cardiovascular diseases in the peripheral blood of periodontitis patients. Jounal of Periodontology,71,1528-1534, 2000.

Lorenzi, T. F. Atlas de Hematologia: Clínica Hematológica llustrada. Rio de Janeiro, Guanabara \& Koogan, 2006, 3-67.

Lundberg, J. O. N; Weitzberg, E.; Lundberg, J.N.; Alving, K. Intragastric nitric oxide prodution in humans: measurements in expeled air. Gut, 35,1543-46, 1994.

Lyu, C. I; Lerner, U. H.; Teng, Y. T. Cytokine responses against periodontal infection: protective and destructive roles. Periodontology 2000, 52, 163-206, 2010.

Mandhane, P. J.; Hanna, S. E. Changes in exhaled nitric oxide related to estrogen and progesterone during the menstrual cycle. Chest Journal, 136(5), 1301-7 2009.

Marcaccini, A. M.; Meschiari, C. A.; Gerlach, R. F. Circulating interleukin-6 and highsensitivity C-reactive protein decrease after periodontal therapy in otherwise healthy subjects. Journal of Periodontology, 80(4), 594-602, 2009a.

Marcaccini, A. M.; Novaes Jr., A. B.; Meschiari, C.A.; Souza, S. L.; Palioto, D.B.; Sorgi, C.A.; Faciolli, L.H.; Tanus-Santos, J.E.; Gerlach, R.F. Circulating matrix metalloproteinase-8 (MMP-8) and MMP-9 are increased in periodontal disease and decrease after non-surgical periodontal therapy. Clinica Chemica Acta,409, 117-122, 2009b. 
Matejka, M.; Partyka, L.; Ulm, C.; Solar, P.; Sinzinger, H. Nitric Oxide synthesis is increase in periodontal disease. Journal of Periodontal Research, 33, 517-8, 1998

Miller, C. S.; Foley, J. D.; Baley, A.L. Current developments in salivary diagnostics. Biomark in Medicine, 4(1), 171-189, 2010.

Moncada, S.; Higgs, E. A. Endogenous nitric oxide: physiology, pathology and clinical relevance, 21, 361-374, 1991.

Murphy, G.; Ward, R.; Gravrilovic, J.; Atkinson, S. Physiologival mechanisms for metalloproteinase activation. Matrix Supplement, 1, 224-230, 1992.

Nagase, H.; Woessner, J. F. Jr. Matrix metalloproteinases. The Journal of Biological Chemestry, 21491-4, 1999.

Nagler, R. M.; Klein, I.; Zarzhevsky, N.; Drigues, N.; Reznick, A. Z. Characterization of the differentiated antioxidant profile of human saliva. Free Radical Biology \& Medicine, 32, 268-77, 2002.

Nawrocki, B.; Polette, M.; Marchand, V.; Monteau, M.; Gillery, P.; Tournier, J. M.; Birembaut, $P$. Expression of matrix metalloproteinases and their inhibitors in human bronchopulmonary carcinomas: quantificative and morphological analyses. International Journal of Cancer, 72(4), 556-64,1997.

Neville, B.; Damm, D. D.; Allen, C. M.; Bouquot, J.E. Patologia Oral \& Maxilofacial. $2^{a}$ Edição. Rio de Janeiro: Guanabara Koogan; 2004, 145-146.

Novak, B.; Genco, R. J.; Trevisan, M.; Grossi, S.; Zambon, J. J.; De Nardin, E. Periodontal infection contribute to elevated systemic C- reative protein level. Journal of Periodontology, 72, 1221-1227, 2001.

O'Connell, Taba Jr, M.; Nomizo, A.; Freitas, M.C.; Suaid, F.A.; Uyemura, S.; Trevisan, G. L.; Novaes Jr., A. B.; Souza, S. L.; Palioto, D. B.; Grisi, M. F. Effects of periodontal therapy on glycemic control and inflammatory markers. Journal of Periodontology, 79(5), 774-778, 2008.

Okamoto, T.; Akaike, T.; Sawa, T.; Miyamoto, Y.; van der Vliet, A.; Maeda, H. Activation of metalloproteinases by peroxinitrite-induced protein $S$ glutathiolation via disulfide S-oxideformation. Journal of Biology Chemistry, 276, 29596-29602, 2001. 
Ozer L., Elgun S., Ozdemir B., Pervane B., Ozmeric N. Arginine-Nitric OxidePolyamine Metabolism in Periodontal Disease. Journal of Periodontology, 82(2), 320-8, 2011.

Ozmeriç, N. Advances in periodontal disease markers. Clinica Chimica Acta, 343, 116, 2004.

Ozmeriç, N.; Elgun, S.; Uraz, A. Salivary arginase in pacients with adult periodontitis. Clinical Oral Investigation, 4, 21-4, 2000.

Page R. C.; Schroeder H.E. Pathogenesis of Inflammatory Periodontal Disease: A Summary of Current Work. Laboratory Investigation, 34, 235-249, 1976.

Page, R. C. Milestones in periodontal research amd the remaing critical issues. Journal of Periodontal Research, 34, 331-9, 1999.

Page, R. C. The role of inflammatory mediators in the pathogenesis of periodontal disease. Journal of Periodontal Reasearch, 26(3), 230-242, 1991.

Palmer, R. M. J.; Ferridge, A. G.; Moncada, S. Nitric oxide accounts for the biological activity of endothelial-derived relaxing factor. Nature, 327, 524-6, 1987.

Parwani, S. R.; Chitnis, P. J.; Parwani, R. S. Salivary nitric oxide in inflammatory periodontal disease- $A$ case control and interventional study. International Journal of Dental Hygiene, 10(1), 67-73, 2011.

Pedersen, A. M.; Bardow, A.;Jensen, B. S.; Nauntofte, B. Saliva and gastrointestinal functions of taste, mastigation, swallowing and digestion. Oral Diseases, 8, 117-29, 2002.

Pinto V. G. Epidemiologia das doenças bucais no Brasil. In: Kriger L. Aboprev: Promoção de saúde bucal. $3^{a}$ edição. São Paulo: Artes Médicas; 1999,27-42.

Radi, R. Nitric oxide, oxidants, and protein tyrosine nitration.Proceedings of the National Academy of Science of the United State of America, 101(12), 40034008, 2004.

Reher, V. G. S.; Zenóbio, E. G.; Costa, F. O.; Reher, P.; Soares, R.V. Nitric oxide levels increase with severity of chronic periodontitis. Journal of Oral Science, 49(4), 271-276, 2007. 
Reynolds, J. J. Collagenases and tissue inhibitors of metalloproteinases: a functional balance in tissue degradation. Oral Disease, 2(1), 70-6, 1996.

Sato, E. F.; Choudhury, T.; Nishikawa, T.; Inoue, M. Dynamic Aspect of Reactive Oxygen and Oxide Nitric in Oral Cavity.Jounal of Clinical Biochemistry and Nutrition, 42, 8-13, 2008.

Schnaper, H. W.; Grant, D. S.; Stetler-Stevenson, W.G.; Frisman, R.; D’Orazi, G.; Murphy, A.N.; Bird, R.E.; Hoythya, M.; Fuerst, T.R.; French, D.L. Type IV collagenase(s) and TIMPs modulate endothelial cell morphogenesis in vitro. Journal of cellular physiology, 156(2), 235-246, 1993.

Schneider, E.; Dy, M. The role of arginase in the immune response. Immunology Today, 6, 136-40, 1985.

Schwahn, C.; Volzke, H.; Robinson, D. M. Periodontal disease, but not endentulism, is independently associated with increase plasma fibrogen levels. Results from a population-based study. Journal of Thrombosis and Haemostasis, 92, 244252, 2004.

Shiboski, T.; Hodgson, J.; Ship, M.; Schiodt, M. Management of salivary hypofunction during and after radiotherapy. Oral Surgery, Oral Medicine, Oral Pathology, Oral Radiology and Endodontology, 103,1-19,2007.

Socranscky S. S.; Haffajee, A. D. Dental biofilms: difficult therapeutic targets, Periodontology 2000, 8(1), 12-55, 2002.

Socransky, S. S.; Haffajee, A. D. Evidence of bacterial etiology: a historical perspective. Periodontology 2000, 5, 7-25, 1994.

Stetler- Stevenson, W. G.; Krutzsch, H. C.; Liotta, L. A. TIMP-2: indentification and characterization of a new member of the metalloproteinase inhinitor family. Matrix Supplement, 1, 299-306, 1992.

Taba,M. Jr.; Kinney, J.; Kim, A. S; Giannobile, W. V. Diagnostic biomarkers for oral and periodontal diseases. Dental Clinics of North American, 49(3), 551-571, 2005.

Tannenbaum, S. R.; Weissman, M.; Fett, B. The effect of nitrate intake on nitrite formation in human saliva, Food and Cosmetic Toxicology, 14, 549-552, 1976. 
Ten Cate, A. R. Histologia Bucal: Desenvolvimento, Estrutura e Função. $5^{\text {a }}$ Edição. Rio de Janeiro: Guanabara \& Koogan, 2001.238-239 a.

Ten Cate, A. R. Histologia Bucal: Desenvolvimento, Estrutura e Função. $5^{\text {a }}$ Edição. Rio de Janeiro: Guanabara \& Koogan, 2001.297 b.

Timmerman, M. F.; van der Weijden, G.A. Risk factors for periodontitis. International Journal of Dental Hygiene, 4,2-7, 2006.

Trusson, M. Sensory-motor function of human periodontal mechanoreceptors. Journal of Oral Rehabilitation, 33, 262-73, 2006.

Turko, I. L.; Murad, F. Protein Nitration in Cardiovascular Disease. Pharmacological Reviews, 54, 619-634, 2002.

Uğar-Çanka, D.; Ozmeric, N. A multifaceted molecule, nitric oxide in oral and periodontal diseases. Clinica Chimica Acta, 366, 90-100, 2006.

Verkman, A. S.; Yang, B. Role of water channels in fluid transport studied by phenotype analysis of aquaporin knockout mice. Experimental Physiology, 85, 233S-241S, 2000.

Vicent, J. L; Baron, J. F., Reinhard, K. Anemia and blood transfusionin critically ill patients. Journal of American Medical Association, 288, 1499-507, 2002.

Vidal, F.; Figueredo, C. M. S.; Cordovil, I.; Fischer, R.G. Periodontal therapy reduces plasma levels of Interleukin-6, C-Reactive Protein, and Fibrinogen in patients with severe periodontits and refractory arterial hypertension. Journal of Periodontology,80,786-791,2009.

Weinberg, J. B.; Lang, T. Serum, urinary, and salivary nitric oxide in rheumatoid arthritis: complexities of interpreting nitric oxide measures. Arthritis Research \& Therapy, $8: 1,2006$. 